Erika Franco de Carvalho

\title{
Estudo do remodelamento ativo da matriz extracelular pulmonar na esclerose sistêmica
}

Tese apresentada à Faculdade de Medicina da Universidade de São Paulo para obtenção do título de Doutor em Ciências

Área de concentração: Patologia

Orientadora: Prof ${ }^{a}$ Dr $^{a}$ Vera Luiza Capelozzi

SÃO PAULO 


\title{
Dados Internacionais de Catalogação na Publicação (CIP)
}

\author{
Preparada pela Biblioteca da
}

Faculdade de Medicina da Universidade de São Paulo

Creprodução autorizada pelo autor

\section{Carvalho, Erika Franco de}

Estudo do remodelamento ativo da matriz extracelular pulmonar na esclerose sistêmica / Erika Franco de Carvalho. -- São Paulo, 2007.

Tese(doutorado)--Faculdade de Medicina da Universidade de São Paulo. Departamento de Patologia.

Área de concentração: Patologia.

Orientadora: Vera Luiza Capelozzi.

Descritores: 1.Matriz extracelular 2.Doenças pulmonares intersticiais 3.Escleroderma sistêmico 4.Manutenção corretiva 5.Inflamação 6.Pneumonia 7.Pulmão 
Há um só Senhor, uma só fé, um só batismo; e um só Deus e Pai de todos, o qual está sobre todos, age por meio de todos e está em todos. Efésios 4:4. 


\section{Agradecimentos}

Sinto-me grata a Deus por ter me dado os meios de começar e finalizar essa etapa de minha vida, de ter colocado em meu caminho tantas pessoas que me ajudaram a terminar essa tese e a quem serei sempre grata.

A meus pais e a minha querida avó Zaíra pela compreensão e apoio constante.

Aos meus irmãos pela solidariedade, dos que só os que passaram por essa fase são capazes de dar.

Ao meu querido Fausto pelo incentivo e ajuda.

A Professora Vera Capelozzi, mulher ímpar, exemplo de força, coragem e determinação. O seu amor pelo ensino sempre ficará marcado na minha memória, bem como a sua importância e dedicação para o desenvolvimento médico-científico do nosso país. Sinto-me muito honrada e agradecida por ter trabalhado sob a sua orientação

Ao meu amigo Edwin Parra pelo seu auxílio, colaboração e paciência inigualáveis.

A Alexandre Muxfeldt Áb Saber, o Xandão, um dos responsáveis por ter despertado meu interesse pela patologia pulmonar durante a residência. Discutir os casos com você e com a Professora Vera e sem dúvida uma das melhores lembranças do meu período de residência.

A Professora Walcir por ter aberto as portas do seu laboratório para a conclusão do nosso estudo e pelo seu carinho. 
A todos do Departamento de Reumatologia e especialmente a Romy por ter nos ajudado com obtenção e análise dos dados clínicos.

A Cássia e a todas as técnicas pela eficiência do seu trabalho.

As meninas da imuno pela imprecindiva ajuda e colaboração.

Ao Professor Paulo Saldiva por ter nos permitido o uso do LIM-05. 
Esta tese está de acordo com:

Referências: adaptado de International Committee of Medical Journals Editors (Vancouver)

Universidade de São Paulo. Faculdade de Medicina. Serviço de Biblioteca e Documentação.

Guia de apresentação de dissertações, teses e monografias. Elaborado por Anneliese Carneiro da Cunha, Maria Júlia de A. L. Freddi, Maria F. Crestana, Marinalva de Souza Aragão, Suely Campos Cardoso, Valéria Vilhena. São Paulo: Serviço de Biblioteca e Documentação; 2005.

Abreviaturas dos títulos dos periódicos de acordo com List of Journals Indexed in Index Medicus. 
SUMÁRIO

Lista de Figuras

Lista de Tabelas

Lista de Abreviaturas

Resumo

Summary

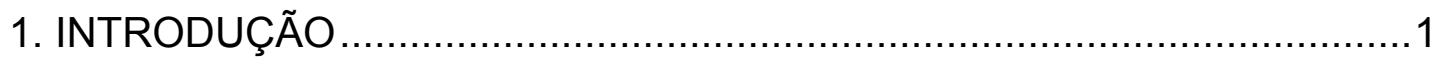

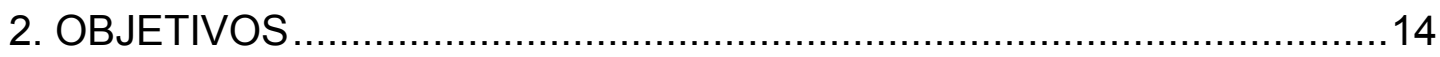

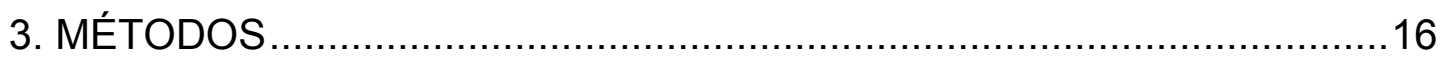

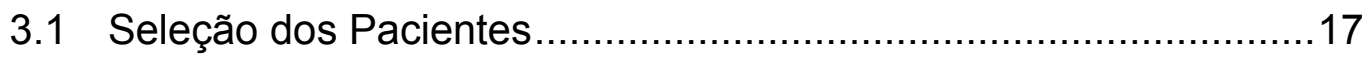

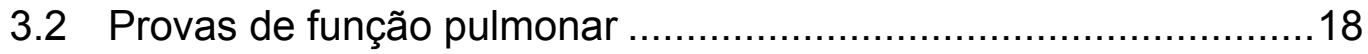

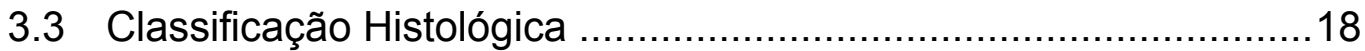

3.4 Análise do Parênquima e da Microvasculatura Pulmonar ..............19

3.5 Quantificação da expressão imuno-histoquímica...........................20

3.6 Análise das Fibras Elásticas e Colágenas ...................................21

3.7 Quantificação das fibras elásticas e do colágeno do interstício

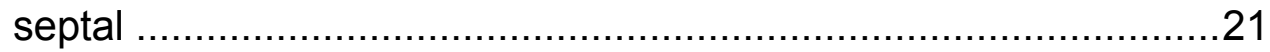

3.8 Quantificação das fibras elásticas e do colágeno vascular ............22

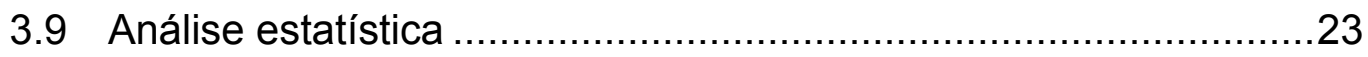

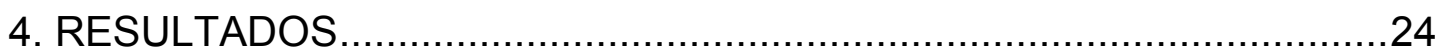

4.1 Análise Qualitativa do Remodelamento/Reparo Parenquimal e

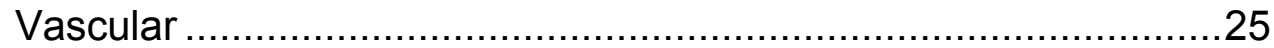

4.2 Análise Quantitativa do Reparo/Remodelamento do Parênquima e da Vasculatura Pulmonar........................................30

4.3 Associação entre Remodelamento/Reparo, Provas de Função Pulmonar e Prognóstico .......................................................... 31

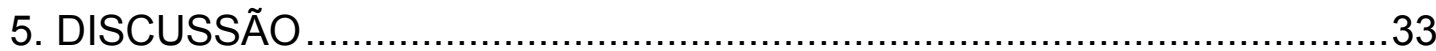

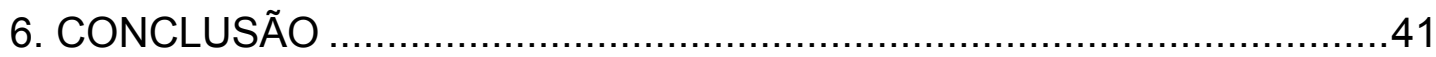


7. ANEXOS

Anexo 1- Histórico das classificações das pneumonias intersticiais idiopáticas.

Anexo 2- Principais doenças difusas do parênquima pulmonar.

Anexo 3- Classificação atual das pneumonias intersticiais idiopáticas (ATS/ERS) e seus correspondentes clínicos .45

Anexo 4- Publicacao originaria da tese. .45

Anexo 5- Artigo originado da tese (submetido ao Histopathology). ......66

8. REFERÊNCIAS 


\section{Lista de figuras}

Figura 1 (A, B, C). Padrao histologico NSIP. A- Hematoxilina eosina 400X; B Resorcina 400X; C Picrosirius 400X.

Figura 2 ( $A, B, C, D, E, F, G, H, I, J)$. Vasos no padrão histológico NSIP com aumento progressivo do grau vascular. A, B, CHematoxilina-eosina 400X. D, F, G Resorcina 400X. H, I, JPicrosirius 400X.

Figura 3 (A, B). Expressão imuno-histoquímica de CK-7 na NSIP-ES (A) e na NSIP-idiopática (B) 400X.

Figura 4 (A, B). Expressão imuno-histoquímica de SP-A na NSIP-ES (A) e na NSIP-idiopática (B) 400X.

Figura 5 ( $A, B$ ). Expressão imuno-histoquímica de CD-34 na NSIP-ES (A), e na NSIP-idiopática (B) 400X.

Figura 6 (A, B). Expressão imuno-histoquímica de VCAM-1 na NSIPES A), , e na NSIP-idiopática (B) 400X. 


\section{Lista de tabelas}

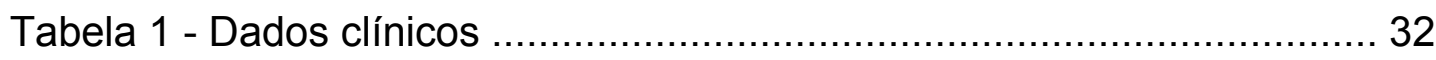

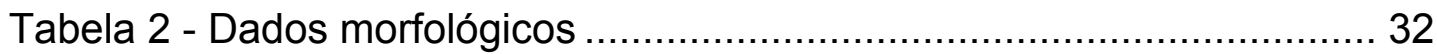




\section{Lista de abreviaturas}

ES : $\quad$ esclerose sistêmica

ILD : doença intersticial parenquimatosa

DLPD: doenças difusas do parênquima pulmonar

NSIP: $\quad$ pneumonia intersticial pulmonar não específica

ATS/ERS : American Thoracic Society

UIP: $\quad$ pneumonia intersticial usual

IPF: fibrose pulmonar idiopática

TCAR: tomografia computadorizada de alta resolução

CK7: $\quad$ anticorpo anti- citoqueratina 7

SP-A: anticorpo anti- proteína-a do surfactante

CD-34: anticorpo anti-marcador de célula endotelial CD-34

VCAM-1: anticorpo anti-molécula de adesão vascular 1

CVF: $\quad$ capacidade vital forçada

VEF1: volume expiratório forçado no primeiro segundo

CPT: $\quad$ capacidade pulmonar total

DCO: capacidade de difusão de monóxido de carbono

DCO-Hb: valor de DCO corrigido pela hemoglobina 


\section{Resumo}

Carvalho EF. Estudo do remodelamento ativo da matriz extracelular pulmonar na esclerose sistêmica [tese]. São Paulo: Faculdade de Medicina, Universidade de São Paulo; 2007. 96p.

Introdução: A doença intersticial pulmonar é um importante fator prognóstico na esclerose sistêmica (ES). O prognóstico das pneumonias intersticiais não específicas (NSIP) associadas às colagenoses tem sido descrito como melhor do que o da forma idiopática. Levanta-se a hipótese de que $o$ processo de remodelamento e reparo do parênquima pulmonar nessas duas formas da doença sejam diferentes. Objetivos: Comparar os mecanismos de reparo e remodelamento entre a NSIP associada a ES e a NSIP idiopática. Observar o impacto dos mesmos nas provas de função pulmonar e na sobrevida. Métodos: Foram analisadas 40 biópsias de pacientes com o diagnóstico de NSIP (18 biópsias de NSIP associada a ES e 22 na forma idiopática). As informações clínicas e as provas de função pulmonar foram obtidas através da revisão dos prontuários. As lâminas foram revisadas por três patologistas. Foram comparadas as densidades epitelial, vascular, bem como a atividade vascular dos dois grupos utilizando o método de imuno-histoquímica. Para isso foram utilizados os anticorpos anti- citoqueratina 7 (CK-7), anti- proteína-a do surfactante (SP-A), antimarcador de célula endotelial CD-34 (CD34), e anti-molécula da adesão vascular 1 (VCAM-1). Também foi comparado o padrão de remodelamento da matriz septal e vascular, usando os métodos histoquímicos da resorcina (fibras elásticas) e picrosírius (colágeno). Uma análise estatística foi realizada comparando os resultados dos dois grupos, o impacto do remodelamento nas provas de função pulmonar e a influência na sobrevida. Resultados: A densidade das células epiteliais foi menor na NSIP-ES, do que na forma idiopática $(p<0,0001)$. Já os pneumócitos tipo II e as células de Clara encontraram-se diminuídos no grupo idiopático $(p=0,02)$. Uma diminuição na densidade vascular foi encontrada na NSIP-ES quando comparada à forma idiopática $(p<0,0001)$; no entanto, a atividade vascular medida pelo VCAM-1 foi maior no grupo da NSIP-ES $(p<0.0001)$. O conteúdo das fibras elásticas e colágeno septal, bem como o das fibras elásticas na parede vascular, estavam aumentados no grupo da ES quando comparados à forma idiopática $(p=0,01 ; p=0,001$ e $p<0,0001$, respectivamente). Não houve diferença estatística entre o colágeno da parede vascular, no grau de obstrução vascular ou associação entre os parâmetros de remodelamento e reparo do parênquima pulmonar na sobrevida dos dois grupos. Dentre as provas de função pulmonar, a DCO/Hb foi mais afetada no grupo da ES (59\% do valor predito na ES e $97 \%$ no grupo idiopático). Foi observada uma associação direta entre a densidade vascular e a $\mathrm{DCO} / \mathrm{Hb} \quad(\mathrm{p}=0,02)$. Após o seguimento de 36 meses, não foi observada diferença no prognóstico dos dois grupos. Conclusão: Os processos de remodelamento e reparo do parênquima pulmonar parecem ser diferentes entre os dois grupos. Apesar de o processo fibrótico ser mais 
intenso na NSIP-ES, isso parece não estar associado a um pior prognóstico, como tem sido descrito na forma idiopática. Como o processo de elastose e a expressão do VCAM-I são mais intensos na ES, isso sugere que o processo inflamatório tem um papel mais importante na patogênese e no processo de remodelamento e reparo da ES do que na forma idiopática. No entanto, outros estudos são necessários para validar a importância desses resultados e sua utilização para fins terapêuticos e de prognóstico.

Descritores: 1.Matriz extracelular 2.Doenças pulmonares intersticiais 3.Escleroderma sistêmico 4.Manutenção corretiva 5.Inflamação 6.Pneumonia 7.Pulmão 


\section{Summary}

Carvalho EF. Study of active pulmonary matrix remodeling process in systemic sclerosis [thesis]. São Paulo: "Faculdade de Medicina, Universidade de São Paulo"; 2007. 96p.

Background: The presence of Interstitial lung disease is a well recognized prognostic factor in systemic sclerosis (SSc). As the prognosis in nonspecific interstitial pneumonia (NSIP) has been described to be better in collagen vascular disorders compared to the idiopathic forms, it is conceivable that the mechanisms of repair and remodeling are different between these two forms of the disease. Objectives: To compare the mechanisms of repair and remodeling between SSc associated nonspecific pneumonia and the idiopathic form, as well as their impact on pulmonary function tests and survival rates. Methods: Biopsies from 18 patients with SSc-associated NSIP and 22 with idiopathic NSIP were analyzed. Clinical data and pulmonary function test results were obtained by retrospective chart review. All H\&E slides were reviewed by three pathologists. The epithelial and vascular densities and vascular activity were compared between the two groups by immunohistochemistry with antibodies directed against cytokeratin-7, surfactant protein-a, CD34, and VCAM-1, as well as septal and vascular matrix remodeling using histochemical stains (picrosirius and resorcin). Statistical analyses were performed to compare the results of these various studies with clinical parameters (e.g. pulmonary function tests) and survival between the groups. Results: Epithelial cell density was lower in SSc-NSIP when compared with idiopathic-NSIP $(p<0.0001)$. Type II pneumocytes and Clara cells were reduced in idiopathic NSIP $(p=0.02)$. A decrease in microvessel density was found in SSc-NSIP compared to idiopathic-NSIP $(p<0.0001)$. The vascular activity measured by VCAM-1 expression was higher in NSIP-SSc when compared to the idiopathic group $(p<0.0001)$. A direct association between vascular density and DLCO/HB was found $(p=0.02)$. Among pulmonary function tests the DLCO/HB was affected to a greater extent in the SSc group (59\% of the predicted value in SSc and $97 \%$ in the idiopatic group). The content of septal collagen and elastic fibers, as well as the elastic fibers in the vascular wall, were higher in the SSc group ( $p=0.01, p=0.001$ and $p<0.0001$, respectively). There were no differences in the collagen content of the vascular wall, vascular grade, or survival between the two groups. There was no difference in the survival rate between the two groups after a follow-up of 36 months. Conclusions: Alterations in the pulmonary epithelium and vasculature seem to differ in the SSc-NSIP when compared to the idiopathic form of the disease. Although the fibrotic process is more intense in the SSc group, it does not seem to affect the prognosis of these patients, contrary to what has been described in idiopatic lung fibrosis. Because the elastotic process and VCAM-1 expression are higher in the SSc group, this might suggest that inflammatory mechanisms affecting the elastic fiber system and vasculature could play a greater role in the pathogenesis and pulmonary 
remodeling process of SSc-NSIP than in idiopathic-NSIP. Further studies may be required to assess the significance of these findings and explore if they can provide prognostic and/or treatment information.

Descriptors: 1.Extracelular matrix 2.Interstitial lung disease 3.Systemic sclerosis 4.Inflamation 5.Pneumonia 6.Lung 


\section{INTRODUÇÃO}


A esclerose sistêmica (ES) é uma doença vascular do colágeno, caracterizada por fibrose exagerada da pele, alterações vasculares, músculo-esqueléticas e comprometimento variável de órgãos internos. O aspecto principal dessa doença é expansão da matriz extracelular secundária à produção exagerada das proteínas da matriz, sendo o colágeno a mais importante. A deposição do colágeno é o resultado da interação anormal entre as células endoteliais, células mononucleares (linfócitos e monócitos) e fibroblastos. Essa interação anormal leva a reatividade vascular exacerbada, hipóxia tecidual e produção de citoquinas pró-fibróticas $(1,2)$

A esclerose sistêmica é uma colagenose de etiologia desconhecida. Vários anticorpos têm sido encontrados no soro desses pacientes. Apesar de os mesmos serem importantes para o diagnóstico e alguns estarem associados com a atividade da doença, a importância desses autoanticorpos na patogênese dessa entidade permanece desconhecida. Outros fatores têm sido implicados como possíveis agentes causadores, os mais importantes sendo a exposição a drogas, exposição ambiental e ocupacional a solventes orgânicos, infecções virais. No entanto o histórico familiar de esclerose sistêmica é o fator de risco mais importante $(2,3)$. 
A patogênese dessa doença envolve vasculopatia obliterante em vários leitos vasculares, inflamação, auto-imunidade e fibrose progressiva. A agressão vascular e ativação das células endoteliais é um dos eventos iniciais na patogênese dessa patologia, possivelmente o evento primário. Essa teoria encontra suporte em evidências histopatológicas, em que se observa que o dano vascular precede a fibrose, e pelas manifestações clínicas que refletem o comprometimento vascular, tais como o fenômeno de Raynaud (vasoespasmo reversível dos vasos dos dedos desencadeado pelo frio), que precede outras manifestações clínicas dessa patologia. Outras manifestações vasculares são a teleangiectasia cutânea, a hipertensão pulmonar arterial, a ectasia vascular gástrica e a crise renal esclerodérmica $(4,5)$.

Acredita-se que a lesão endotelial possa ser desencadeada por enzimas, anticorpos específicos contra as células endoteliais, vírus de ação vasculotrópica, citoquinas inflamatórias, radicais reativos do oxigênio gerados durante episódios de isquemia/reperfusão. A agressão a essas células leva a ativação e disfunção das mesmas, aumento da permeabilidade capilar, aumento da expressão da molécula de adesão vascular do tipo I (VCAM-I), molécula de adesão endotelial leucocitária do tipo I (moléculas que facilitam a migração das células inflamatórias), secreção alterada de mediadores vasoativos, ativação de plaquetas e das vias fibrinolíticas $(4,5,6)$.

As células endoteliais ativadas liberam endotelina do tipo I, um potente vasoconstrictor que também promove adesão leucocitária, proliferação de células musculares lisas dos vasos e ativação dos 
fibroblastos. A lesão vascular leva a um remodelamento dos vasos (hipertrofia da camadas íntima e média, fibrose da camada adventícia), resultando numa progressiva diminuição da luz vascular e obliteração. Esse conjunto de reações inflamatórias e de auto-imunidade leva à ativação dos fibroblastos por vias diretas e indiretas, o que leva à fibrose progressiva (5).

A forma de apresentação clínica dessa patologia é heterogênea, sendo seu curso variável e imprevisível. Os pacientes com esclerose sistêmica são geralmente classificados de acordo com o comprometimento dérmico em dois grupos: a forma limitada onde se observa um envolvimento dérmico e sistêmico limitado; a forma difusa, com comprometimento dérmico e visceral extenso. Estes, secundários à fibrose, às anormalidades na microvasculatura e ao infiltrado inflamatório linfocitário comumente vistos no trato gastrintestinal, pulmões, coração e rins (1).

O envolvimento pulmonar é freqüente nesta colagenose, sendo a principal causa de mortalidade entre esses pacientes. Uma das formas de acometimento desse órgão é o comprometimento do interstício pulmonar, podendo o mesmo ser observado em 25 a $90 \%$ dos pacientes, dependendo do método utilizado para a investigação (7-12).

O interstício pulmonar é formado por dois componentes: o celular, constituído principalmente pelas células intersticiais (fibroblastos, miofibroblastos e pericitos) e pelas células inflamatórias (fagócitos mononucleares, linfócitos e mastócitos); e o não celular ou matriz extracelular pulmonar (MEC), formado predominantemente por colágeno, fibras elásticas e proteoglicanos. Os fibroblastos sintetizam a maior parte dos componentes 
não celulares do interstício como colágeno do tipo I e III, elastina, fibronectina, sulfato de heparina, sulfato de condroitina e ácido hialurônico. Por interstício pulmonar subentende-se o compartimento entre as membranas basais das células epiteliais alveolares, englobando também a área em torno do eixo vásculo-brônquico. Esse compartimento estende-se desde os septos alveolares até a pleura, sendo, portanto, errônea a limitação deste espaço à área situada apenas entre as células alveolares $(13,14)$.

O comprometimento do interstício pulmonar caracteriza as doenças intersticiais pulmonares (ILD), ou doenças difusas do parênquima pulmonar (DLPD), um grupo heterogêneo de doenças não neoplásicas, formado por aproximadamente 200 entidades que apresentam em comum características clínicas, radiológicas e histopatológicas. Na maioria dessas doenças, o interstício, bem como outras estruturas pulmonares (pleura, vias aéreas, vasos sanguíneos, células epiteliais dos alvéolos e bronquíolos), são acometidos. Por essa razão alguns autores preferem o termo doença difusa do parênquima pulmonar (15).

As doenças intersticiais pulmonares difusas geralmente envolvem ambos os pulmões, podendo se manifestar de maneira aguda, subaguda ou crônica. Os principais fatores implicados na etiologia são a exposição ambiental e ocupacional, as doenças do colágeno e as doenças granulomatosas. No entanto, o grupo mais importante dentre as pneumonias intersticiais é a forma idiopática (15). Quadro I - Anexo 1.

A pneumonia intersticial é caracterizada por expansão do compartimento septal por células inflamatórias, fibrose secundária à 
deposição anormal de colágeno e proliferação de fibroblastos. Esses também capazes de sintetizar colágeno, contribuindo, portanto, para a deposição de colágeno (14).

O diagnóstico histológico das doenças difusas do parênquima pulmonar difere do das doenças neoplásicas. De uma forma geral, os vários tipos de neoplasia que acometem um órgão são diferenciados entre si pelo aspecto histológico distinto, sendo estes, algumas vezes, únicos daquela entidade. Na diferenciação das doenças difusas do parênquima pulmonar, outros achados morfológicos são levados em consideração, sendo importante a localização do processo (compartimento anatômico ou estruturas acometidas), a distribuição (focal ou difusa) e a composição celular da reação inflamatória (aguda, crônica, histiocítica) (14).

Liebow e colaboradores foram os primeiros a tentar classificar as pneumonias intersticiais. Esses autores observaram que o pulmão apresenta formas limitadas de resposta (padrão histológico) frente às mais diversas formas de agressão. Um determinado fator etiológico pode levar a diferentes padrões de resposta pulmonar, bem como um mesmo padrão histológico pode ser secundário a diferentes agentes agressores. Essa teoria é a base de todas as classificações posteriores (16). Quadro II - Anexo 1.

Em 1994, Katzenstein e colaboradores descreveram a pneumonia intersticial pulmonar não específica (NSIP). Nessa época, NSIP era usado como termo descritivo e não como diagnóstico específico. A mesma estaria associada a doenças do colágeno, à exposição a drogas, a pneumonia de hipersensibilidade e à forma idiopática. Com a evolução desse termo, seu 
uso tem sido restrito à forma idiopática. Entretanto, segundo alguns autores, a NSIP é um padrão de resposta, presente em vários contextos clínicos, dentre os quais estaria a forma idiopática (17-19).

Segundo o consenso da ATS/ERS de 2001, as pneumonias intersticiais idiopáticas dividem-se em sete grandes grupos, cujo diagnóstico baseia-se em achados clínicos-radiológicos-histopatológicos. Os grupos são: a pneumonia intersticial usual (UIP), clinicamente conhecida como fibrose pulmonar idiopática (IPF) ou alveolite fibrosante criptogênica; a pneumonia macrofágica alveolar; a pneumonia em organização; o dano alveolar difuso; a pneumonia intersticial não específica (NSIP) e a pneumonia intersticial linfocítica. Para fins didáticos, essa classificação pode ser resumida em dois padrões principais: pneumonia intersticial usual e a pneumonia intersticial não específica $(14,18)$. Quadro III - Anexo I.

A pneumonia intersticial usual (UIP) é a forma mais comum de pneumonia intersticial idiopática, estando presente em até $60 \%$ dos casos. Geralmente acomete pacientes entre $5^{a}$ e $7^{a}$ décadas de vida, sendo mais freqüente no sexo masculino. Dentre os fatores de risco, o tabagismo é o único que está bem estabelecido; outros fatores como vírus e predisposição familiar também têm sido sugeridos $(14,15,18)$.

O estabelecimento da sintomatologia é insidioso, podendo preceder o diagnóstico em seis a 24 meses. Entre as manifestações clínicas, a dispnéia é o sintoma mais incapacitante. A tosse seca é bastante comum e é, na maioria das vezes, refratária a agentes antitussígenos. O baqueteamento digital é visto em $25 \%$ a $50 \%$ dos 
pacientes. Estertores finos inspiratórios, inicialmente confinados às bases, são encontrados na ausculta pulmonar. O curso clínico é invariavelmente de uma deterioração gradual. Esta patologia não responde ao tratamento, sendo a sobrevida a partir da época do diagnóstico em média de 2,5 a 3,5 anos $(14,15,18)$.

A tomografia computadorizada de alta resolução (TCAR) demonstra a presença de opacidades reticulares usualmente associadas a bronquiectasia por tração, alterações em favo de mel, atenuação em vidro fosco e distorção arquitetural. Essas alterações são encontradas nas regiões basais e periféricas do pulmão. O teste de função pulmonar revela uma doença de padrão restritivo e uma diminuição da capacidade de difusão do monóxido de carbono. O aspecto morfológico é de fibrose de padrão temporal e espacial heterogêneos, focos de fibroblastos, alterações em favo de mel, destruição arquitetural e inflamação intersticial de leve a moderada $(15,18)$.

A pneumonia intersticial não específica estaria presente em 14 a $34 \%$ dos casos. Acomete mais as mulheres, entre a faixa etária de 46 a 57 anos. A média de duração dos sintomas antes do diagnóstico é de oito a 18 meses. Os sintomas são dispnéia, tosse e cansaço. Perda de peso está presente em $50 \%$ dos pacientes. Ao exame físico, estertores nas bases são usualmente encontrados. O prognóstico é melhor do que o da UIP, sendo a sobrevida em cinco anos de $90 \%$. A resposta à terapia é satisfatória $(15,18,19)$.

Na tomografia, áreas de atenuação em vidro despolido, usualmente extensas, são vistas em quase todos os casos. O padrão reticular, apesar de 
estar comumente presente, raramente é uma alteração predominante. Os testes de função pulmonar revelam um padrão restritivo com redução da DCO. Histologicamente, NSIP é caracterizada por um espessamento septal difuso, homogeneidade temporal e fibrose em organização focal $(14,15,18,19)$.

Em estudos realizados em autópsias, a fibrose pulmonar associada à esclerose sistêmica foi considerada indistinguível da forma idiopática. No entanto, em estudos realizados em biópsias pulmonares, observou-se que a fibrose pulmonar na esclerose sistêmica tem um prognóstico melhor do que a forma idiopática e uma melhor resposta à terapia. Esses relatos foram feitos antes da atual classificação da ATS (18-21).

Na época da realização desses estudos, as duas formas principais de pneumonia intersticial eram consideradas a mesma entidade, ou seja, a NSIP e a UIP, hoje conhecidas, pertenciam ao grupo da pneumonia intersticial usual ou comum, descrita por Liebow. O termo UIP, de Liebow e colaboradores, era usado como sinônimo de doença crônica pulmonar fibrosante, e englobava variadas formas de fibrose pulmonar 16. Com a evolução das classificações, UIP tornou-se o padrão histológico da entidade clínica fibrose pulmonar idiopática, doença benigna irresponsiva à terapêutica e de prognóstico sombrio (18).

Com o uso da classificação da ATS/ERS das pneumonias intersticiais, tem-se observado que o padrão histológico mais relacionado com a ES é a NSIP. Isso explicaria o melhor prognóstico e melhor resposta à terapia nesse grupo, já que, na forma idiopática, a UIP é mais prevalente e seu prognóstico desfavorável. No entanto, Bouros e colaboradores, na maior série já 
publicada sobre pneumonia intersticial associada a ES, observaram que a NSIP-ES tinha um melhor prognóstico que a NSIP idiopática. A UIP-ES também apresentava um melhor prognóstico que a UIP-idiopática e que não havia diferença prognóstica entre a NSIP-ES e a UIP-ES, como ocorre na pneumonia intersticial idiopática. Outros autores acreditam que na colagenose há uma melhor resposta à terapia e, portanto, os pacientes não evoluem para uma fibrose mais intensa $(22,24,25,26)$.

A matriz extracelular pulmonar é constituída pela membrana basal do epitélio alveolar, do epitélio das vias aéreas e do endotélio dos capilares e pelo tecido intersticial pulmonar. Tem como função principal prover suporte estrutural, impedindo o colapso alveolar; permitir a variação do volume pulmonar durante inspiração e expiração; facilitar a difusão gasosa entre os alvéolos e a rede capilar (13).

Para entendimento dos diferentes cursos das pneumonias intersticiais, idiopática e associada à colagenose, é preciso recordar os mecanismos de reparo que se seguem à lesão tecidual. Secundariamente à lesão pulmonar, instala-se um processo de reparação, que consiste numa rápida restauração da integridade dos tecidos e das suas funções. O reparo normal é o resultado de uma integração complexa entre os fatores humorais e celulares da matriz extracelular levando a uma seqüência de eventos como coagulação, inflamação, formação de tecido de granulação e restabelecimento da relação entre as células estromais e do parênquima $(27,28)$.

Na fibrose pulmonar ocorre um aumento na matriz e alteração no número e na distribuição espacial das células do parênquima pulmonar. 
O aumento da ECM resulta da proliferação e ativação de fibroblastos com deposição de macromoléculas da matriz na área da lesão. O tecido conjuntivo ativado está associado a um aumento na expressão de genes produtores de colágeno, de fibronectina, de proteoglicanas, entre outros. Há também alterações no citoesqueleto, na expressão dos receptores e também nas enzimas que degradam a matriz e seus inibidores. A reação fibroproliferativa envolve a participação de uma variedade de citoquinas e mediadores da inflamação liberados por células inflamatórias que se encontram no local da lesão. O espessamento da parede alveolar pode ser secundário à deposição de ECM dentro do interstício ou como resultado da incorporação mural do exudado em organização nos espaços aéreos $(27,28)$.

Considera-se que a pneumonia intersticial associada à esclerose sistêmica seja resultado de uma série complexa de reações inflamatórias de origem auto-imune que ocorreriam no interstício. Outros fatores importantes para a patogênese dessa entidade são a persistente ativação, a falta de regulação dos genes que codificam o colágeno e outras proteínas da matriz extracelular, a alteração na produção de citoquinas pró-inflamatórias e prófibróticas e produção de fatores de crescimento. Acredita-se que na forma idiopática o componente inflamatório tenha um papel secundário $(29,30)$.

Independente da sua etiologia, as doenças fibroproliferativas, como a fibrose pulmonar idiopática, a esclerose sistêmica, a cirrose hepática, a doença degenerativa macular, têm em comum uma alteração no processo de cicatrização levando à fibrose. Vários fatores podem lesar os tecidos, entre eles, os estímulos inflamatórios agudos e crônicos, as reações auto- 
imunes e o estresse mecânico são os principais. Seguindo-se à agressão tecidual, instala-se o processo de reparo. Dois mecanismos envolvem esse processo. O primeiro é o regenerativo, onde as células que sofreram lesão são substituídas por células idênticas, não deixando evidências da agressão. O segundo é o mecanismo fibroproliferativo, onde as células parenquimatosas são substituídas por tecido conjuntivo. Apesar de inicialmente benéfico, o processo de cicatrização pode se tornar aberrante resultando no remodelamento da matriz extracelular e na formação de tecido cicatricial (fibrótico) permanente, podendo levar ao comprometimento na função dos órgãos (31).

Nas reações inflamatórias agudas, as alterações vasculares, bem como o edema e o infiltrado inflamatório neutrofílico são rapidamente resolvidos. Essa resolução não ocorre na inflamação crônica, na qual os processos de inflamação, reparo e lesão tecidual ocorrem ao mesmo tempo, levando à desorganização do processo de cicatrização e fibrose. As doenças fibróticas, apesar de suas características clínicas e etiológicas diferentes, parecem ter em comum um estímulo persistente, que propiciaria a produção contínua de fatores de crescimento, de enzimas proteolíticas, de fatores angiogênicos e de citoquinas fibrogênicas. A ação conjunta dessas substâncias estimularia a deposição de elementos do tecido conjuntivo, culminando com o remodelamento progressivo e destruição da arquitetura do tecido/órgão (31).

Vários fatores, tais como a raridade da esclerose sistêmica, a ausência de modelos animais que reproduzam a tríade da patogênese da 
doença (vasculopatia dos pequenos vasos, inflamação/auto-imunidade, fibrose intersticial e vascular) e a não indicação de biópsias pulmonar na ILD associada a ES, contribuem para o desconhecimento e para as controvérsias na patogênese dessa doença.

De acordo com a fundamentação científica anteriormente apresentada, verifica-se a existência de hiatos na literatura que expliquem as diferenças da patogênese, do curso clínico e do prognóstico do comprometimento pulmonar por NSIP associado a ES. Levanta-se a hipótese de que as diferenças podem estar relacionadas a diferentes mecanismos de reparo/remodelamento do parênquima pulmonar. Dessa forma o objetivo deste estudo foi comparar os mecanismos de reparo/remodelamento do parênquima pulmonar na NSIP idiopática e na NSIP associada a esclerose sistêmica. 
2. OBJETIVOS 
Estudar as diferenças entre os mecanismos de reparo, regeneração e remodelamento pulmonar na NSIP-ES e na forma idiopática, com ênfase nos componentes epitelial, endotelial, sistema elástica/colágeno vascular e septal. Verificar associação entre os mecanismos de reparo/regeneração e remodelamento com as provas de função pulmonar e sobrevida. 
3. MÉTODOS 


\subsection{Seleção dos Pacientes}

Biópsias pulmonares de 40 pacientes, 18 com NSIP-ES e 22 com NSIP idiopática foram analisadas. Seus diagnósticos foram confirmados segundo os critérios do último consenso da classificação de pneumonias intersticiais da American Thoracic Society/European Respiratory Society (ATS/ERS). As biópsias incluídas nesse estudo preenchiam todos os critérios da referida classificação. Nenhuma das biópsias apresentava extensiva alteração em favo de mel (pulmão terminal), ou mais de um aspecto histológico (dois padrões histológicos diferentes, na amostra de um mesmo paciente). A presença de etiologias associadas, como por exemplo, pneumoconioses e outras doenças do colágeno, foram afastadas (18).

O prognóstico foi calculado após 36 meses da data da biópsia.

Os pacientes com esclerose sistêmica foram diagnosticados segundo os critérios definidos pelo Colégio Americano de Reumatologia (32).

Os tecidos pulmonares foram obtidos por toracotomia tradicional. A biópsia a céu aberto foi guiada por tomografia computadorizada de alta resolução (TCAR). Foram obtidos dois ou três fragmentos de tecido representando áreas normais, intermediárias e mais comprometidas. Áreas de faveolamento foram evitadas. 


\subsection{Provas de função pulmonar}

As provas de função pulmonar foram realizadas num período de um a três meses antecedentes à biópsia. A função pulmonar foi avaliada pela espirometria, pela determinação dos volumes pulmonares e pela capacidade de difusão do monóxido de carbono (DCO) realizada pelo aparelho Collins GS (Collins Medical囚).

Os parâmetros de função pulmonar incluídos foram capacidade vital forçada (CVF), volume expiratório forçado no primeiro segundo (VEF1) e a relação entre VEF1/CVF. A capacidade pulmonar total (CPT) e o volume residual (VR) foram determinados pela técnica de diluição do Helio. A DCO foi analisada pelo método de respiração única. Os resultados destes testes foram expressos pelos valores preditos conforme idade, sexo e altura, de acordo com as recomendações da Sociedade Torácica Americana. A DCO foi corrigida pela hemoglobina dosada na época da realização do teste de função pulmonar $(33,34)$.

\subsection{Classificação Histológica}

As biópsias foram revisadas por três patologistas desconhecedores dos diagnósticos clínicos dos pacientes.

As mesmas foram rotineiramente fixadas em formol a $10 \%$ e coradas pela Hematoxilina \& Eosina ( $\mathrm{HE})$. O diagnóstico histopatológico de 
pneumonia intersticial não específica foi definido por espessamento septal inflamatório, homogeneidade temporal e mínima área de fibrose em organização 18 (figura 1).

Os vasos foram graduados, seguindo o sistema de classificação de Heath-Edwards: grau I - hipertrofia isolada da media arterial; grau II - lesão proliferativa da camada íntima; grau III - oclusão total do lúmen arterial por tecido fibroso; grau IV - lesão plexiforme (35).

Foram obtidas amostras de tecido pulmonar normais, de cinco autópsias de pacientes que morreram por causas traumáticas (idade média $60 \pm 3,6$ anos). Nenhum dessas amostras, utilizadas como controles, apresentavam critérios histológicos para diagnóstico de pneumonia intersticial, ou outra patologia pulmonar.

\subsection{Análise do Parênquima e da Microvasculatura Pulmonar}

Foram avaliadas as células epiteliais e endoteliais do parênquima pulmonar, bem como o grau de atividade inflamatória dos capilares, usando a técnica imuno-histoquímica de peroxidase da avidina-biotina. Para o estudo das células epiteliais, foram usados os anticorpos anti-citoqueratina 7 (CK7) (Clone OV-TL 12/30; Dako, Glostrup, Dinamarca; diluição 1:100 ), que reconhece os pneumócitos tipo I e II e células epiteliais brônquicas. $O$ anticorpo apoproteína-A do surfactante (SP-A) (Clone PE10; Dako, Carpinteria; CA, EUA; diluição, 1:800) foi utilizado para a identificação dos 
pneumócitos tipo II e células de Clara. As células endoteliais vasculares foram avaliadas usando o anticorpo marcador de células endoteliais CD-34 (CD-34) (Clone QBEnd/10; Novocastra Laboratórios Ltd, Newcastle, Reino Unido; diluição, 1:400). O grau de atividade vascular inflamatória foi analisado usando o anticorpo policlonal anti-molécula de adesão vascular 1 (VCAM-1) (Santa Cruz Biotecnologia , Inc, Santa Cruz, Ca; diluição, 1:8000).

\subsection{Quantificação da expressão imuno-histoquímica}

O estudo da densidade epitelial e vascular, bem como da atividade vascular, foi feito através da quantificação das células que expressavam marcação por CK-7, SP-A, CD34, VCAM-1. Foram estudados 10 campos microscópicos, por caso, num aumento 400X. Utilizou-se um retículo com 100 pontos e 50 retas, em uma das oculares. Foram consideradas positivas as células que expressavam os anticorpos e atingiam os pontos do retículo. O número de pontos sobre as células foi anotado, e contado o número de pontos que atingiu o espaço aéreo. Subtraindo-se o número total de pontos do número de pontos no espaço aéreo, obteve-se o número de pontos que atingia o tecido. $O$ índice de imunoexpressão foi obtido pela relação entre o número de pontos sobre as células imunomarcadas e o número total de pontos no tecido em porcentagem. Obteve-se a média dos 10 campos analisados por caso. O resultado final foi a porcentagem de expressão do anticorpo por área sólida (36). 


\subsection{Análise das Fibras Elásticas e Colágenas}

As fibras colágenas foram coradas usando Sirius red a 2\% (Direct Red 80, C. I. 35780, Aldrich, Milwaukee, WI 53233, EUA) dissolvido em solução aquosa de ácido pícrico. Este corante impregna as fibras colágenas permitindo a visualização e a quantificação das mesmas. O aumento da birrefringência é dado pela polarização do picrosírius que permite uma melhor visualização e quantificação das estruturas colágenas. As fibras elásticas podem ser estudadas após tratamento com o método de Weirgert Resorcina-Fucsina oxidada (37).

\subsection{Quantificação das fibras elásticas e do colágeno do interstício septal}

A quantificação de ambas as fibras foi feita através de um sistema de análise de imagem. O sistema consiste de uma câmera JVC TK-C1380 acoplada a um microscópio Leika. Através desse sistema digital (Oculus TCX, Coreco inc; St Laurent, Quebec, Canadá) as imagens são capturadas e transferidas a um computador (Pentium3 300Mhz). As mesmas são processadas por um software (Image ProPlus). Um total de 10 campos por biópsia foi estudado num aumento de 400 X. Para cada lâmina o sistema foi ajustado, a fim de ser obtido um grau máximo de contraste, tornando as fibras elásticas (pretas) e fibras colágenas (birrefringente) facilmente identificáveis. A 
área ocupada pelas fibras foi medida por um sistema digital densitométrico capaz de determinar a quantidade de fibras elásticas e colágenas por área delimitada. Para evitar viés secundário ao edema septal ou ao colapso alveolar, a área sólida alveolar também foi medida. Com esses resultados calculamos a razão dessas duas medidas e como resultado tivemos a quantidade de fibras elásticas e colágenas por área sólida (área real do septo intersticial, excluindose área de edema e de colapso) por campo microscópico. Foi feita uma média dos 10 campos e o resultado final foi expresso em porcentagem.

\subsection{Quantificação das fibras elásticas e do colágeno vascular}

O colágeno da camada média e as fibras elásticas dos grandes vasos foram medidos usando o mesmo sistema e seguindo os mesmos princípios acima descritos. A área da parede vascular de cada artéria foi determinada por um sistema que permitia medir da membrana elástica interna até a membrana elástica externa (luz do vaso foi excluída). Nessa área (área vascular) foi determinada a quantidade das referidas fibras. Foi calculada a razão entre o conteúdo de fibras e a área vascular. Uma média do total de vaso por lâmina foi calculada. O resultado obtido foi o de conteúdo de fibras elásticas e colágeno por área vascular. O mesmo foi expresso em porcentagem. 


\subsection{Análise estatística}

A média e o desvio padrão foram calculados para cada parâmetro estudado e colocados em uma tabela. Uma análise estatística descritiva foi realizada. Seu resultado foi mantido em arquivos bem como os gráficos dos mesmos. Para comparação entre os grupos foram usados os testes $\mathrm{T}$ ou ANOVA com Bonferroni quando apropriado. Foram realizadas curvas de sobrevivência comparando os diversos marcadores imuno-histoquímicos e histoquímicos na NSIP-ES e NSIP idiopática pelo método de Kaplan-Meier. O estudo estatístico foi realizado com o programa SPSS versão 10.0 (SPSS, Inc., Chicago, IL). O nível de significância foi estabelecido $p<0,05$. 
4. RESULTADOS 
A idade média dos pacientes com NSIP-ES (18 pacientes do sexo feminino) foi de 45,82 $\pm 2,19$ anos; a dos pacientes com NSIP idiopática (10 pacientes do sexo masculino e 12 do feminino) foi de 50,81 $\pm 2,17$ anos. Dispnéia estava presente em 17 e em 18 dos pacientes dos referidos grupos respectivamente. Os dados clínicos e demográficos podem ser observados na Tabela 1.

\subsection{Análise Qualitativa do Remodelamento/Reparo Parenquimal e Vascular}

Os aspectos morfológicos observados usando os métodos de coloração H\&E, resorcina-fucsina de Weigert e picrosírius polarizado não diferiram nos dois grupos. Ambas as formas de NSIP apresentavam espessamento septal inflamatório, com fibrose mínima e manutenção da arquitetura septal. (Figura 1-A). As fibras elásticas apresentavam-se alteradas. Podiam ser observadas áreas de ruptura das fibras, bem como áreas de proliferação das mesmas. (Figura 1-B). Com o método de picrosírius, foi visualizada, na área de espessamento intersticial, uma birrefringência vermelho-alaranjada (Figura 1-C). 


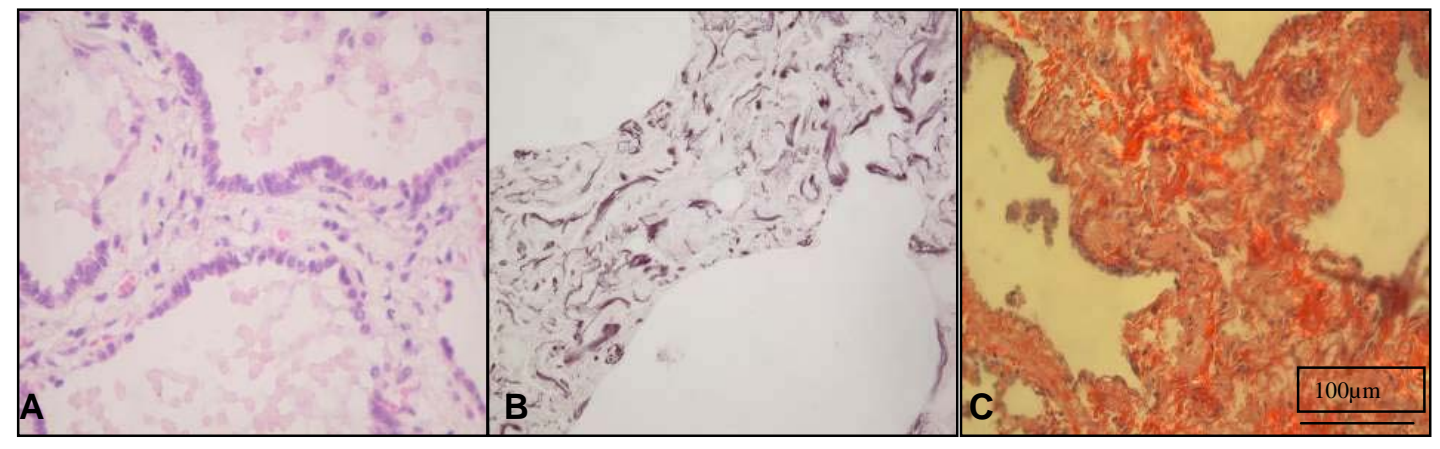

Figura 1. Padrão histológico NSIP no aumento de 400X. A- HE, B- resorcina, C- picrosírius.

Foram observados três diferentes graus de obstrução vascular: grau I (Figura 2- A ), grau II (Figura 2-B ), grau III (Figura 2-C ). Uma proliferação progressiva das fibras elásticas da camada interna e externa da parede vascular foi observada com o aumento do grau de remodelamento (grau vascular): grau I (Figura 2-D), grau II (Figura 2-E) e grau III (Figura 2-F). Visualizou-se uma distorção da arquitetura vascular com aumento da birrefringência das camadas vasculares nos três tipos de grau de obstrução vascular: grau I (Figura 2-G), grau II (Figura 2-H) e grau III (Figura 2-I). 

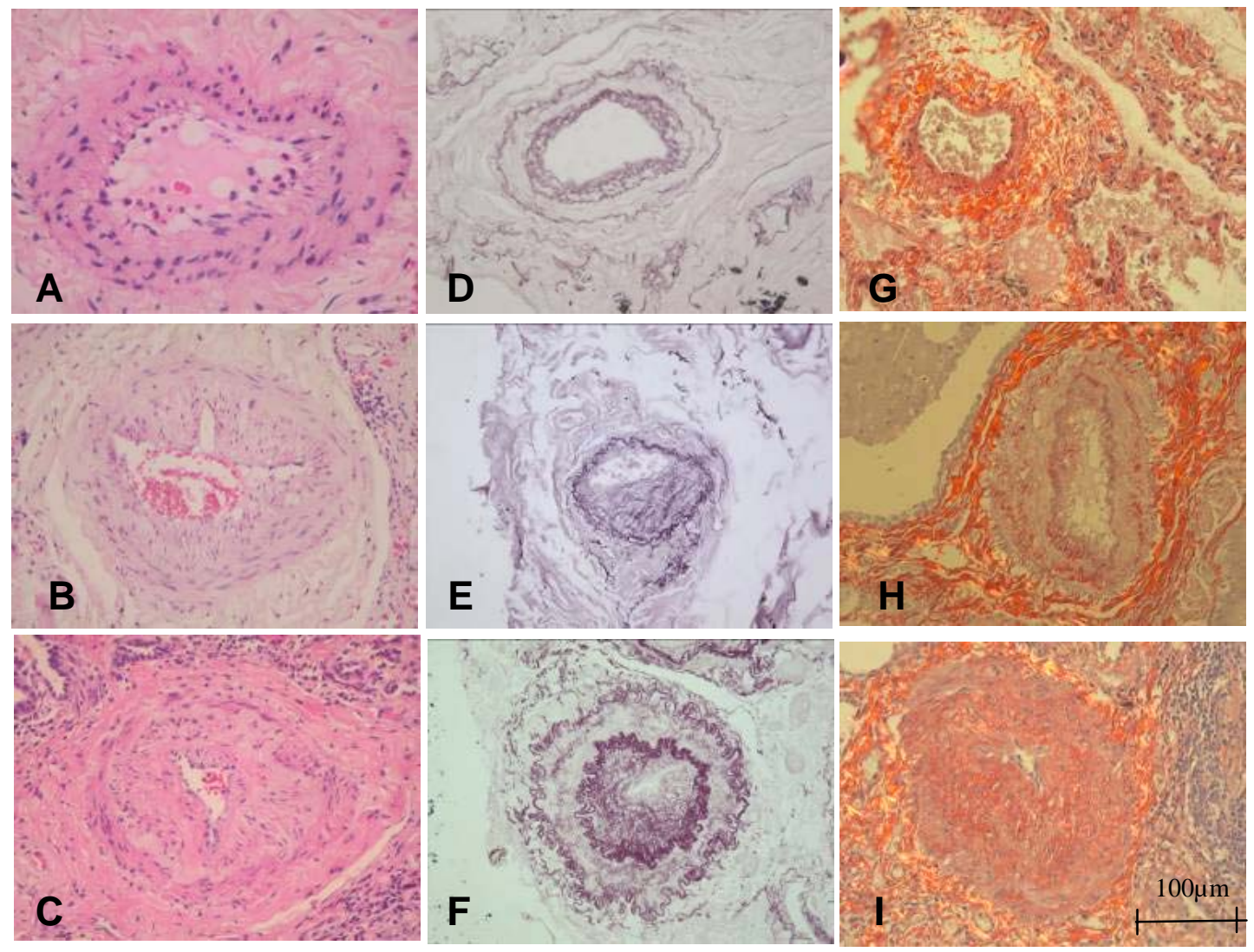

Figura 2. Ao HE observa-se artérias com aumento progressivo do grau vascular $(A, B, C)$. Com a coloração de resorcina observa-se uma deposição gradual de elástica que acompanha o aumento do grau vascular (D,E,F). Com a coloração de picrosírius observa-se uma deposição de coágeno que acompanha o aumento da grau vacular $(\mathbf{G}, \mathrm{H}, \mathrm{I})$.

Tanto na NSIP-ES quanto na forma idiopática houve uma expressão difusa e homogênea das células imunomarcadas pelo CK-7 (Figura 3-A e 3-B) e SP-A (Figura 4-A e 4-B). A localização das células imunomarcadas coincidiu com o espessamento septal inflamatório visualizado no H\&E (Figura 1-A). 

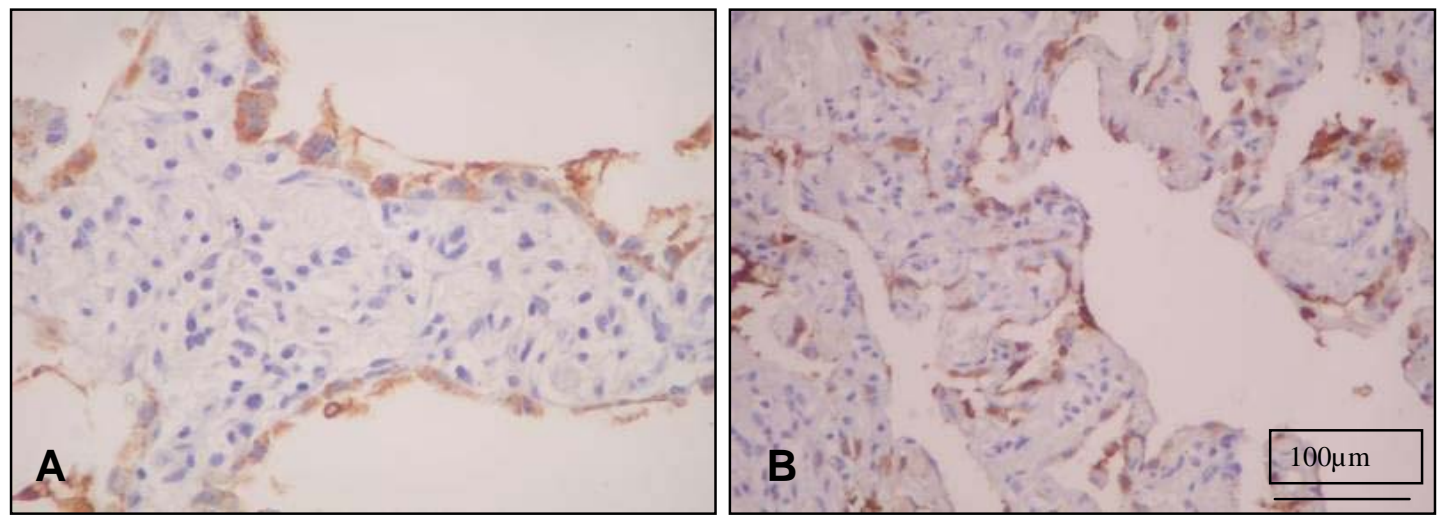

Figura 3. Observa-se distribuição difusa do CK7, em 3-A NSIP associada a esclerose sistêmica e em 3-B NSIP idiopática.
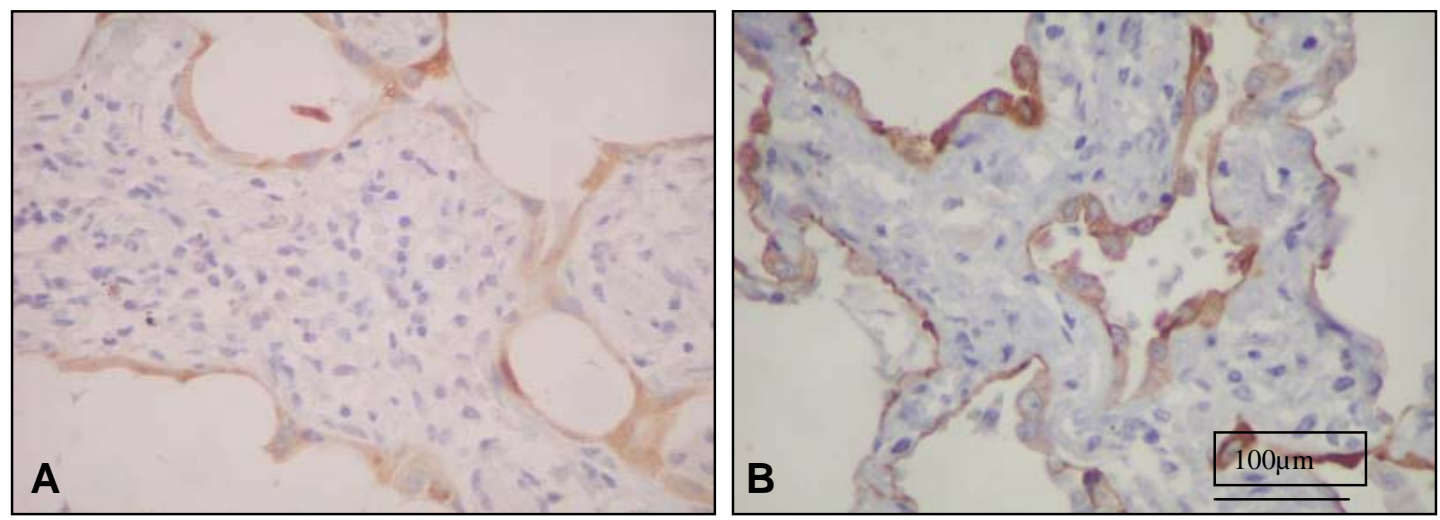

Figura 4. Observa-se distribuição difusa do SP-A, em 4-A NSIP associada a esclerose sistêmica e em 4-B NSIP idiopática.

O CD34 apresentou uma distribuição uniforme nas células endoteliais capilares de ambos os grupos, NSIP-ES (Figura.5-A) e NSIPidiopático (Figura. 5-B). Nas áreas de espessamento septal, os capilares da NSIP-ES (Figura 5A) apresentaram-se mais dilatados e em número diminuído, quando comparados à forma idiopática (Figura 5B). Nesta última forma, observou-se uma proliferação septal mais homogênea 
(Figura 5B). As células endoteliais na NSIP-ES (Figura 6A), apesar de diminuídas quando comparadas à forma idiopática (Figura 6B), apresentaram uma maior expressão de VCAM-1.
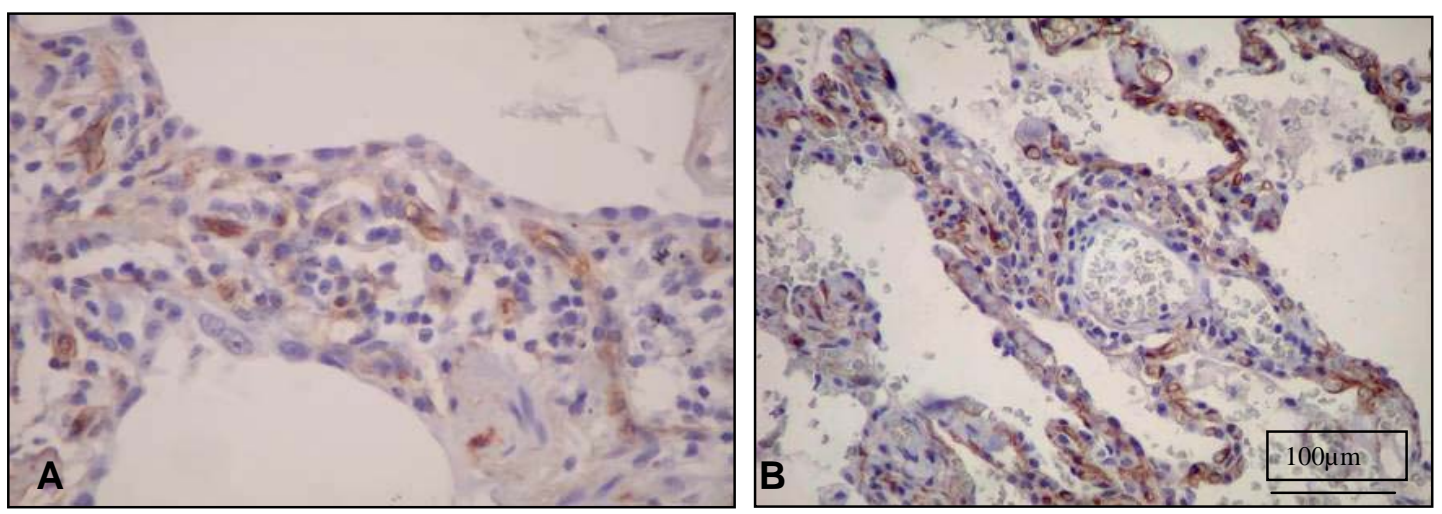

Figura 5. Observa-se distribuição difusa dos capilares, marcados pelo CD34. 5-A NSIP associada a esclerose sistêmica, 5-B NSIP-idiopática
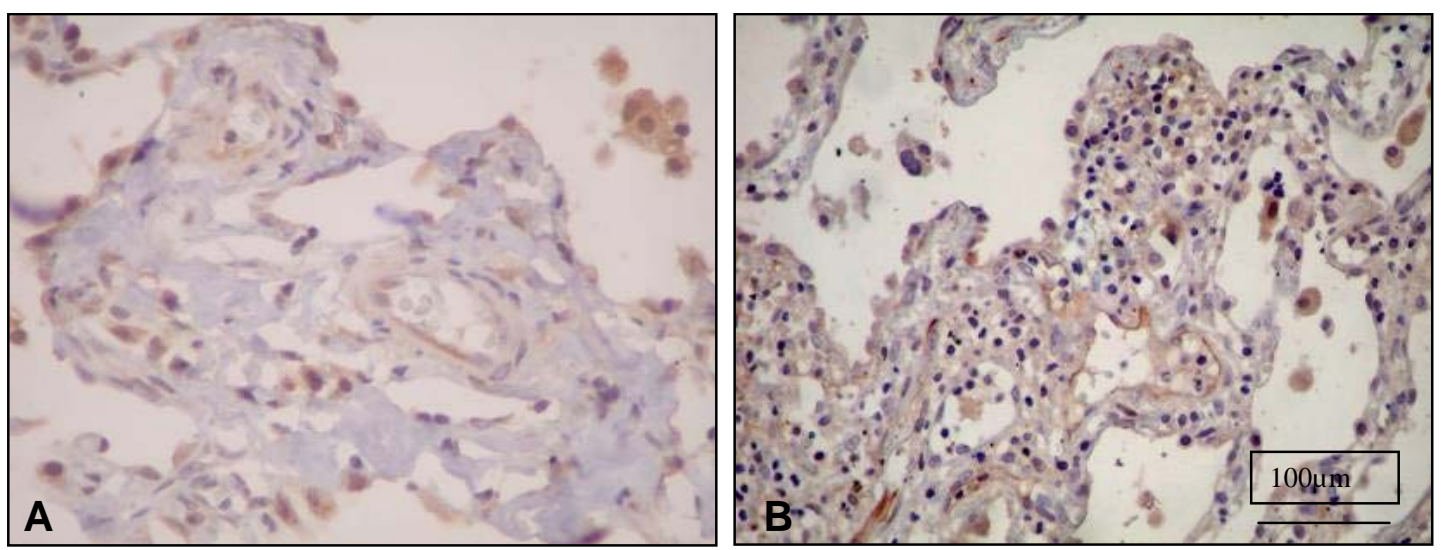

Figura 6. Observa-se distribuição difusa dos capilares, marcados pelo VCAM-1. 6-A NSIP associada a esclerose sistêmica, 6-B NSIP-idiopática. 


\subsection{Análise Quantitativa do Reparo/Remodelamento do Parênquima e da Vasculatura Pulmonar}

A densidade das fibras colágenas no interstício septal foi maior na NSIP-ES quando comparada à forma idiopática. Essa diferença apresentou significância estatística $(29,9 \pm 17,10$ vs $14,46 \pm 2,58, p=0,01)$. O colágeno vascular na NSIP-ES apresentou uma tendência ao aumento quando comparado à forma idiopática, mas não houve diferença estatística $(31,46 \pm 21,41$ vs $3,85 \pm 0,82, p=0,26)$. A comparação das fibras elásticas do septo intersticial entre os dois grupos revelou um aumento significante na NSIP-ES $(12,72 \pm 4,02$ vs $7,26 \pm 2,70, p=0,001)$. Um aumento similar pode ser notado nas fibras elásticas dos vasos $(41,68 \pm 11,20$ vs $25,50 \pm 3,20$, $p<0,0001)$. Não houve diferença no grau vascular entre os dois grupos; no entanto, uma associação direta foi encontrada entre a densidade de fibras elásticas nos vasos e o grau vascular $(p=0,001)$.

A densidade das células epiteliais medidas pela expressão do CK-7 foi menor no grupo NSIP-ES quando comparado ao grupo idiopático $(5,33 \pm 1,77$ vs $11,46 \pm 3,39, p<0,0001)$. As células epiteliais tipo II e as células de Clara, medidas pela expressão do SP-A, mostraram-se diminuídas na forma idiopática quando comparadas à forma associada a ES $(7,02 \pm 2,77$ vs $14,45 \pm 11,21 ; p=0,02)$

Observou-se uma diminuição na densidade microvascular na NSIP-ES quando comparada à NSIP-idiopática, através da expressão do CD-34 pelas células endoteliais $(4,94 \pm 1,47$ vs $11,69 \pm 1,47 ; p<0,0001)$. 
No entanto, a atividade vascular, medida pela expressão do VCAM-1 apresentou-se aumentada na NSIP-ES quando comparada à forma idiopática $(3,84 \pm 0,97$ vs $0,67 \pm 0,06, p<0,0001)$.

A Tabela 2 demonstra os resultados morfológicos.

\subsection{Associação entre Remodelamento/Reparo, Provas de Função Pulmonar e Prognóstico}

Todos os pacientes apresentaram uma função pulmonar de padrão restritivo, caracterizada por uma diminuição na média da CPT na NSIP-ES (76.44\%) e na NSIP-idiopática (63.25\%) dos valores preditos e aumento na fração FEV1/FVC ×100 [ média na NSIP-ES (69.56\%) e na NSIP-idiopática (104.45\%)]. A DCO apresentou-se diminuída em ambos os grupos, NSIP-ES (53.9\%) e NSIP-idiopático (43\%) (Tabela 1). Uma diferença significante foi encontrada na $\mathrm{DCO} / \mathrm{Hb}$ quando comparada à forma associada à esclerose sistêmica e à forma idiopática $(59,44 \%$ vs $97 \%$; $p<0,0001$ (Tabela 1$)$. Uma associação direta foi observada entre a densidade vascular (CD-34) e a $\mathrm{DCO} / \mathrm{Hb}(p=0,02)$.

Após o seguimento de 36 meses, dois pacientes com a forma idiopática evoluíram a óbito (seis e 10 meses). Os pacientes com NSIP associada à esclerose sistêmica permaneceram vivos. Não houve diferença estatística entre o prognóstico dos dois grupos de NSIP. Da mesma forma, o prognóstico não foi diferente com relação a idade, provas de função 
pulmonar, ou características do remodelamento/reparo do parênquima pulmonar e vascular.

Tabela 1 - Dados clínicos

\begin{tabular}{cccc}
\hline & NSIP-ES & NSIP-idiopático & Teste-T \\
\hline IDADE (anos) & $45,82 \pm 9,04$ & $50,81 \pm 10,21$ & \\
SEXO (F/M) & $18 / 0$ & $12 / 10$ & \\
FEV1 (\%pr) & $69,56 \pm 12,30$ & $58,15 \pm 22,08$ & 0,11 \\
CVF (\%pr) & $65,25 \pm 15,03$ & $54,62 \pm 18,68$ & 0,10 \\
FEV1/CVF & $69,56 \pm 12,30$ & $104,45 \pm 25,16$ & 0,73 \\
CPT (\%pr) & $76,44 \pm 13,56$ & $63,25 \pm 10,53$ & 0,10 \\
VR (\%pr) & $116,44 \pm 49,91$ & $94,50 \pm 43,39$ & 0,40 \\
DCO (\%pr) & $53,90 \pm 14,15$ & $43,00 \pm 28,18$ & 0,50 \\
DCO/Hb(\%pr) & $59,44 \pm 19,74$ & $97,00 \pm 2,83$ & $<0,0001$ \\
\hline
\end{tabular}

$\mathrm{CVF}=$ Capacidade Vital Forçada. VEF1= Volume Expiratório Forçado no primeiro segundo. CPT = Capacidade Pulmonar Total. DCO= Capacidade de Difusão de Monóxido de Carbono. $\mathrm{DCO}-\mathrm{Hb}=$ valor de DCO corrigido pela hemoglobina. $\mathrm{P}<0,05$ foi significante.

Tabela 2 - Dados morfológicos

\begin{tabular}{lcccc}
\hline & NSIP-ES & NSIP-idiopático & Teste-T \\
\hline Colágeno vascular & $31,46 \pm 21,41$ & $3,85 \pm 0,82$ & 0,27 \\
Fibras elásticas vascular & $41,68 \pm 11,20$ & $25,50 \pm 3,20$ & $<0,0001$ \\
Colágeno intersticial & $29,90 \pm 17,10$ & $14,46 \pm 2,58$ & 0,01 \\
Fibras elásticas intersticiais & $12,72 \pm 4,02$ & $7,26 \pm 2,70$ & 0,001 \\
Densidade vascular (CD-34) & $4,94 \pm 1,47$ & $11,69 \pm 1,47$ & $<0,0001$ \\
Atividade vascular (VCAM-1) & $3,84 \pm 0,97$ & $0,67 \pm 0,06$ & $<0,0001$ \\
Citoqueratina 7 (CK-7) & $5,33 \pm 1,77$ & $11,46 \pm 3,39$ & $<0,0001$ \\
Proteina A do surfactante (SP-A) & $14,45 \pm 11,21$ & $7,02 \pm 2,77$ & 0,02 \\
\hline
\end{tabular}


5. Discussão 
O presente estudo comparou o remodelamento/reparo da NSIP-ES e NSIP-idiopática. A questão de interesse é se informações morfológicas adicionais, obtidas estudando o componente parenquimatoso e vascular, podem ajudar a identificar diferenças em prognóstico.

O processo de reparo, regeneração e remodelamento é formado por uma série de eventos seqüenciais e complexos. Tem sido demonstrado que o pulmão de mamíferos pode se regenerar e voltar a crescer. Em experimentos feitos em animais, foi observado que, seguindo-se a ablação cirúrgica parcial do parênquima pulmonar, ocorre uma proliferação do componente epitelial e mesenquimal, levando a uma restituição do volume pulmonar a valores pré-operatórios. A interação entre os componentes vasculares e epiteliais é considerada fundamental para uma restitution ad integrum. Não se sabe se esse processo também ocorre em humanos. Em relação às doenças pulmonares intersticiais, os processos de reparo e remodelamento parecem ter uma importância maior. Depois de uma lesão, o epitélio alveolar inicia um processo semelhante à cicatrização, no intuito de restaurar a barreira alvéolocapilar, caracterizado por uma rápida re-epitelização das áreas desnudas. Tal fenômeno ocorre devido à migração, proliferação e diferenciação das células epiteliais. Seguindo-se a perda ou lesão das células epiteliais tipo I (pneumócitos tipo I), observa-se uma hiperplasia das células epiteliais tipo II 
(pneumócitos tipo II) e uma expressão alterada de moléculas de adesão e de antígenos de histocompatibilidade. Segue-se o recrutamento, proliferação de células inflamatórias, células endoteliais, fibroblastos, e de outras células capazes de sintetizar colágeno, levando deposição da matriz extracelular e conseqüente remodelamento do parênquima pulmonar (38-44).

O processo de remodelamento, tanto da matriz do septo intersticial quanto dos vasos, é um evento dinâmico. O mesmo envolve alterações no sistema de fibras elásticas e colágeno, resultando em diferentes graus de espessamento septal e oclusão vascular. As fibras colágenas encontramse distribuídas no interstício septal e no interstício periaventicial, sendo sintetizadas por fibroblastos, miofibroblastos e células musculares. A função principal dessas fibras é manter a força de tensão que impede a distensão exagerada do parênquima pulmonar durante os movimentos respiratórios e impede a dilatação exagerada dos vasos. No septo alveolar normal, as fibras elásticas estão localizadas na camada subepitelial. Sua função primordial é permitir a restauração do parênquima pulmonar à sua configuração anterior, quando cessado o estímulo inspiratório (45-48).

Nas artérias elásticas normais, essas fibras são encontradas na camada interna e na camada externa, sendo elas as responsáveis pela complacência desses vasos, sendo, portanto, importantes para um funcionamento adequado dos vasos (49-50).

Comparando a NSIP-ES e a forma idiopática, observou-se uma diferença quantitativa na densidade das células epiteliais tipo I e tipo II. 
O número de células epiteliais tipo I, medido pela expressão do anticorpo CK-7, foi menor no grupo da ES. Já o número das células epiteliais tipo II e células de Clara, medido pela expressão do anticorpo SP-A, foi menor na forma idiopática.

Esses achados demonstram que na NSIP-ES o processo de reparo estaria associado a um grau de remodelamento maior do que na forma idiopática. Já o processo de reparo na forma idiopática parece favorecer a regeneração. Estudos anteriores demonstraram a relação entre a lesão epitelial e o grau de fibrose na pneumonia intersticial idiopática. O presente estudo, no entanto, sugere que a caracterização epitelial pode trazer maiores informações acerca da restauração do tecido pulmonar na NSIP-ES e na NSIP-idiopática (51).

Também, no atual estudo, encontrou-se diferenças entre os dois grupos quanto ao padrão de remodelamento dos vasos. Foi observada uma redução no número de capilares medidos pela expressão do anticorpo CD-34 na NSIP-ES. A diminuição na vasculatura pode ser explicada como uma conseqüência da fibrose, apoiando-se em estudos anteriores que descreveram uma redução dos capilares nas áreas de fibrose da pneumonia intersticial usual. Já nas áreas não fibróticas da pneumonia intersticial usual foi observado um aumento relativo do número de capilares. Esses achados corroboram outros estudos realizados pelo grupo de patologia pulmonar desta instituição. No entanto, estudos recentes acreditam que na esclerose sistêmica haja uma diminuição das células progenitoras CD-34, bem como, uma diminuição na maturação dessas células o que diminuiria a vasculogênese. A diminuição do 
número de capilares na ES está também associado a mecanismos auto-imunes que agridem esses vasos $(52,53,54,55)$.

O antígeno VCAM-1 é uma proteína associada à membrana vascular que contribui para o extravasamento vascular de linfócitos, monócitos, basófilos e eosinófilos, particularmente em regiões de inflamação. A quantificação do VCAM-1 permite a avaliação da atividade inflamatória vascular. No presente estudo, a atividade inflamatória foi maior na NSIP-ES do que na forma idiopática, levando a crer que o componente inflamatório vascular tem um papel mais importante na etiogênese da patologia pulmonar dessa colagenose do que na forma idiopática. Ainda no presente estudo uma relação inversa foi encontrada entre o número de capilares (CD-34) e a atividade inflamatória (VCAM-1) em ambos os grupos. Esses achados corroboram outros estudos realizados pelo grupo de patologia pulmonar dessa instituição $(52,56)$.

Quanto ao processo de remodelamento do sistema de fibras elásticas e colágenas do interstício e dos grandes vasos, este estudo demonstrou que não há diferenças qualitativas no processo das duas formas de pneumonia intersticial. No entanto existem diferenças quantitativas significantes. Encontrou-se um aumento das fibras colágenas septais na NSIP-ES quando comparadas à forma idiopática. As fibras colágenas na parede dos grandes vasos apresentaram uma tendência ao aumento na forma associada à ES. Provavelmente a significância não tenha sido atingida devido ao pequeno número de casos, bem como ao grande desvio padrão. 
As fibras elásticas intersticiais e dos vasos apresentaram-se aumentadas na NSIP-ES quando comparadas à forma idiopática. Também foi observada uma associação entre o grau vascular e as fibras elásticas da parede vascular, demonstrando a importância do aumento dessas fibras no grau de obstrução vascular.

Um componente importante das fibras elásticas é a elastina, uma proteína formada pela tropoelastina, um precursor solúvel de $72 \mathrm{kd}$. A destruição da elastina está associada a certas condições patológicas. Um desses mecanismos está associado à liberação de proteases elastolíticas por células inflamatórias. Após um aumento da destruição da elastina, observa-se um incremento na sua síntese. No entanto, esta síntese ocorre de forma desordenada, trazendo conseqüências deletérias às propriedades mecânicas do pulmão, favorecendo o colapso. A resolução do processo inflamatório também se torna prejudicada. Estudos recentes usando modelos animais relatam o aumento da expressão do gene da elastina após certos tipos de lesão, sugerindo a participação das fibras elásticas no processo de reparo (57-60).

Em estudos realizados em lavado brônquico demonstrou-se um aumento da colagenase e da elastase nos neutrófilos de pacientes com fibrose pulmonar associada à esclerose sistêmica. Como o processo de destruição das fibras elástica e posterior elastose parece ser secundário à agressão inflamatória, o aumento dessas fibras na ES encontrado no presente estudo, associado ao aumento da atividade inflamatória dos vasos, sugere que o componente inflamatório é maior na NSIP associada a ES $(61,62)$. 
O processo fibrótico foi mais exuberante na NSIP-ES. Este achado seria facilmente explicado pela natureza fibrosante da ES. No entanto, o aumento da colagenase no lavado brônquico dos pacientes, associado ao fato de que apenas $15 \%$ dos pacientes com pneumonia intersticial associada a ES evoluem para o pulmão fibrótico terminal, demonstra que os mecanismos de fibrose são mais complexos ao envolverem mecanismos opostos de produção e destruição do colágeno, que possivelmente se equilibrariam, o que impediria a evolução da fibrose pulmonar (29).

A fibrose pulmonar densa é associada a um pior prognóstico, sendo considerada um marcador histológico de agressividade. É interessante que, no presente estudo, apesar da maior deposição de colágeno no grupo da NSIP-ES, não se encontrou um pior prognóstico nesse grupo, o que poderia representar um viés secundário ao curto seguimento, ou ser devido a diferenças ultra-estruturais desse colágeno, uma vez que os fibroblastos nos pacientes com pneumonia intersticial associada à colagenose parecem ter características genéticas diferentes daqueles encontrados nas doenças intersticiais idiopáticas $(5,18)$.

No presente estudo, todos os pacientes apresentaram um padrão restritivo da função pulmonar, com uma diminuição semelhante do VPT, $\mathrm{DCO}$, e aumento do fração $\mathrm{FEV}_{1} / \mathrm{FVC}$. Classicamente, o padrão restritivo é uma das características das pneumonias intersticiais. Nesse estudo evidenciou-se uma diminuição maior da DCO-Hb no grupo da ES. Também foi observada uma relação direta entre a densidade vascular e o $\mathrm{DCO} / \mathrm{Hb}$. Como os vasos são importantes para as trocas gasosas, a 
diminuição dos mesmos representa um dos fatores contribuintes para uma menor difusão (18).

Durante o seguimento de 36 meses, dois pacientes do grupo NSIPidiopático evoluíram a óbito. No entanto, não foram observadas diferenças com significância estatística no prognóstico dos dois grupos, ou de acordo com a idade, provas de função pulmonar ou características do remodelamento e reparo do parênquima pulmonar.

Uma das grandes limitações do presente estudo foi o curto seguimento dos pacientes. Este fato poderia tornar indetectável uma pequena diferença na sobrevida entre os dois grupos, o mesmo se aplicando à influência do remodelamento na sobrevida. 
6. Conclusão 
Ambas as formas de NSIP apresentaram remodelamento do parênquima pulmonar independente da forma de agressão. Apesar da semelhança histológica, o remodelamento difere quantitativamente nos dois grupos. Esses achados poderão influenciar novas terapêuticas e o desenvolvimento de tratamentos específicos no futuro. No entanto é necessário protocolos com maior número de pacientes, bem como estudos prospectivos com longo seguimento para validar a importância dos resultados atuais e expandi-los a outras pneumonias intersticiais associadas às doenças do colágeno e à forma idiopática. 
7. Anexos 


\section{Anexo 1}

Histórico das classificações das pneumonias intersticiais idiopáticas.

\begin{tabular}{|c|c|c|}
\hline Liebow 1969 & Katzenstein 1997 & Muller \& Colby 1997 \\
\hline $\begin{array}{c}\text { Pneumonia intersticial } \\
\text { Usual }\end{array}$ & $\begin{array}{c}\text { Pneumonia intersticial } \\
\text { Usual }\end{array}$ & $\begin{array}{c}\text { Pneumonia Intersticial } \\
\text { Usual }\end{array}$ \\
\hline $\begin{array}{c}\text { Pneumonia intersticial } \\
\text { Descamativa }\end{array}$ & $\begin{array}{l}\text { Pneumonia intersticial } \\
\text { Descamativa/bronquiolite } \\
\text { respiratória com doença } \\
\text { pulmonar intersticial }\end{array}$ & $\begin{array}{c}\text { Pneumonia intersticial } \\
\text { descamativa }\end{array}$ \\
\hline $\begin{array}{c}\text { Bronquiolite obliterante } \\
\text { com pneumonia em } \\
\text { organização }\end{array}$ & - & $\begin{array}{c}\text { Bronquiolite obliterante } \\
\text { com pneumonia em } \\
\text { organização }\end{array}$ \\
\hline- & $\begin{array}{c}\text { Pneumonia intersticial } \\
\text { aguda }\end{array}$ & $\begin{array}{c}\text { Pneumonia intersticial } \\
\text { aguda }\end{array}$ \\
\hline - & $\begin{array}{c}\text { Pneumonia intersticial não } \\
\text { específica }\end{array}$ & $\begin{array}{l}\text { Pneumonia intersticial } \\
\text { não específica }\end{array}$ \\
\hline $\begin{array}{c}\text { Pneumonia intersticial } \\
\text { linfocitária }\end{array}$ & - & - \\
\hline $\begin{array}{c}\text { Pneumonia intersticial de } \\
\text { células gigantes }\end{array}$ & - & - \\
\hline
\end{tabular}

\section{Anexo 2}

Principais doenças difusas do parênquima pulmonar

\section{Doenças intersticiais pulmonares}

1. Pneumonia intersticial idiopática

2. Manifestações crônicas das doenças do colágeno

3. Pneumonia eosinofílica crônica

4. Reação a drogas

5. Doenças intersticiais com granulomas (sarcoidose, berilose, pneumonia de hipersensibilidade)

6. Hemorragia alveolar difusa

7. Pneumoconiose

8. Hipertensão pulmonar

9. Doenças variadas (Histiocitose das células de Langerhans, linfangioleiomiomatose, proteinose alveolar pulmonar, amiloidose)

10. Neoplasias malignas (carcinomatose, linfoma, sarcoma metastático) 


\section{Anexo 3}

Classificação atual das pneumonias intersticiais idiopáticas (ATS/ERS) e seus correspondentes clínicos

\begin{tabular}{|c|c|}
\hline FORMAS HISTOLÓGICAS & DIAGNÓSTICOS CLíNICOS \\
\hline Pneumonia intersticial usual & $\begin{array}{c}\text { Fibrose pulmonar idiopática } \\
\text { Alveolite fibrosante criptogênica }\end{array}$ \\
\hline Pneumonia alveolar macrofágica & $\begin{array}{c}\text { Pneumonia alveolar macrofágica } \\
\text { Bronquiolite respiratória com doença } \\
\text { intersticial pulmonar }\end{array}$ \\
\hline Bronquiolite respiratória & Pneumonia em organização \\
\hline $\begin{array}{c}\text { Pneumonia em organização } \\
\text { criptogênica }\end{array}$ & Pneumonia intersticial aguda \\
\hline Dano alveolar difuso & Pneumonia intersticial não específica \\
\hline Pneumonia intersticial não específica & Pneumonia intersticial linfocítica \\
\hline Pneumonia intersticial linfocítica
\end{tabular}

\section{Anexo 4}

\section{Publicacao originaria da tese}

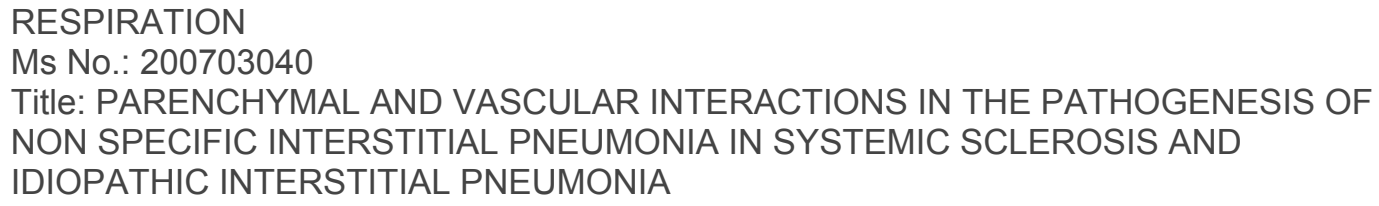

Dear Dr. Parra,

Thank you for submitting a revised version of your manuscript to the journal Respiration. We are pleased to inform you that is has now been accepted for publication and forwarded to the Editing and Production Department who will be contacting you shortly.

We hope you will continue to submit work from your group to Respiration in the future.

With kind regards,

Linda Haas

Respiration

Editorial Office

S. Karger AG - Medical and Scientific Publishers

e: res@karger.ch

f: +4161306 1434

t: +41613061357

w: www.karger.com/res 
PARENCHYMAL AND VASCULAR INTERACTIONS IN THE PATHOGENESIS OF NON SPECIFIC INTERSTITIAL PNEUMONIA IN SYSTEMIC SCLEROSIS AND IDIOPATHIC INTERSTITIAL PNEUMONIA

Erika Franco de Carvalho ${ }^{1}, \mathrm{MD}$, Edwin Roger Parra, ${ }^{1} \mathrm{MD}, \mathrm{PhD}$, Romy de Souza ${ }^{2}, M D$, PhD, Alexandre Muxfeldt A`b Saber ${ }^{1}, M D$, PhD, Vera Luiza Capelozzi ${ }^{1}, \mathrm{MD}, \mathrm{PhD}$

Departments of Pathology ${ }^{1}$ and Rheumatology ${ }^{2}$ University of Sao Paulo Medical School

\section{Corresponding author:}

Vera Luiza Capelozzi, MD, PhD or Edwin Roger Parra, MD, PhD

Departamento de Patologia

Faculdade de Medicina da Universidade de São Paulo

Av. Dr. Arnaldo 455; ZIP CODE - 01246-903, São Paulo, SP, Brazil.

Phone - (5511)3066-7427; FAX - (5511)5096-0761

E-mail - vcapelozzi@lim05.fm.usp.br erparra20003@yahoo.com.br

This study was supported by the following Brazilian agencies: the National Council for Scientific and Technological Development [CNPq]; the Foundation for the Support of Research of the State of São Paulo [FAPESP 2000/14336-0]; and the Laboratories for Medical Research [LIM 05], Clinicas Hospital, School of Medicine, University of São Paulo.

Running title: parenchymal and vascular alterations in nonspecific pneumonia 


\section{ABSTRACT}

Background: Interstitial lung disease is a well recognized prognostic factor in systemic sclerosis (SSc). As the prognosis in nonspecific interstitial pneumonia (NSIP) has been described to be better in collagen vascular disorders compared to the idiopathic forms, we hypothesize that the mechanisms of repair and remodeling are different between these two forms of the disease.

Objectives: To compare the mechanisms of repair and remodeling between SSc associated nonspecific pneumonia and the idiopathic form, its impact on pulmonary function tests and survival rates.

Methods: We analyzed 18 biopsies from patients with NSIP associated with SSc and 22 with idiopathic NSIP and compared the epithelial and vascular densities as well as vascular activity.

Results: Epithelial cell density was lower in SSc-NSIP when compared with idiopathic-NSIP $(p<0.0001)$. Type II pneumocytes and Clara cells were reduced in idiopathic NSIP ( $p=0.02)$. A decrease in microvessel density was found in SSc-NSIP compared to idiopathic-NSIP $(p<0.0001)$. The vascular activity measured by VCAM expression was higher in NSIP-SSc when compared to the idiopathic group $(p<0.0001)$. The DLCO/VA in SScNSIP was more compromised. A direct association between vascular density and DLCO/VA was found $(p=0.02)$. There was no difference in the survival rate between the two groups after a follow-up of 36 months.

Conclusions: Alterations in the epithelium and vasculature seem to differ in the pathogenesis of SSc-NSIP when compared to the idiopathic form of the 
disease. Further studies may be required to assess the significance of these findings and explore if they can provide prognostic and/or treatment information.

Keywords: systemic sclerosis, nonspecific interstitial pneumonia, lung, fibrosis, matrix remodeling, vascular activity, angiogenesis 


\section{INTRODUCTION}

Systemic sclerosis (SSc) is a connective tissue disease (CTD) characterized by vascular abnormalities, fibrosis of the skin, musculoskeletal manifestations and internal organ involvement ${ }^{1}$. Pulmonary involvement in SSc in the form of interstitial pulmonary disease (ILD) occurs in $25-90 \%$ depending on the sensitivity of the evaluation ${ }^{2-6}$, and is a significant cause of morbidity and mortality in this patient population ${ }^{2-7}$.

After the latest consensus statement that divided idiopathic interstitial pneumonias into histological subsets ${ }^{8}$, several studies have been conduced to identify the major histologic patterns associated with CTD. In this context, nonspecific interstitial pneumonia (NSIP) has been found to be the most common histologic pattern in this group of diseases and specifically in SScILD $^{9-12}$. The largest cohort studied in SSc has shown that SSc-NSIP has a better prognosis than idiopathic-NSIP ${ }^{12}$. It is well established in the literature that usual interstitial pneumonia (UIP) associated with CTD has a better outcome compared to the idiopathic form as well as a better response to therapy ${ }^{13}$. Regarding NSIP the literature is controversial. According to some authors CTD-NSIP responds better to therapy, and this may prevent progression to a more fibrotic stage ${ }^{14,15}$. Consequently, there is great interest to identify which NSIP groups are likely to progress to a more fibrotic pattern that may result in shorter patient survival. In addition, identification of these specific NSIP groups after surgical lung biopsy may allow for optimal treatment approaches. 
Few authors have attempted to evaluate the different cellular components, including the epithelium, mesenchyme, vessels, as well as extracellular matrix, to discover what NSIP groups might be associated with progression of fibrosis, treatment response, or shortened survival ${ }^{16-20}$. The loss of lung structure at the parenchymal and vascular levels results in mechanical stress and hypoxia. These factors can trigger several mechanisms which are designed to compensate for the structural and functional loss: lung regeneration, lung repair and lung remodeling ${ }^{21-23}$. In the best-case scenario, these mechanisms result in functional restitution. Because differences in regeneration, repair and remodeling have been thought to be important to structural and functional improvement of the lung, epithelial-vascular interactions have been identified as potentially useful markers ${ }^{16-20}$. Interactions between lung parenchymal cells and angiogenesis have important effects on cellular proliferation, migration, phenotype and production of extracellular matrix, and may also be involved in the pathogenesis of idiopathic and SSc pulmonary fibrosis ${ }^{21-2}$. To validate the importance of epithelial-vascular interactions and to explore the quantitative relationship between these factors and outcome as well as the relationship between these factors and other clinical data and PFT, we studied these markers in 22 cases of idiopathic non specific interstitial pneumonia (idiopathic-NSIP) and 18 with nonspecific interstitial pneumonia and SSc (SSc-NSIP), and herein report our results. 


\section{METHODS}

\section{Patient selection}

From 1979 to 2006, 673 surgical lung biopsies for a confident clinicopathologic diagnosis were performed in our Institution. Among these cases, a total of 40 out of 82 specimens with a histological pattern of non-specific interstitial pneumonia (NSIP) unanimously reclassified according to the American Thoracic Society / European Respiratory Society consensus classification ${ }^{8}$ by two lung pathologists, with sufficient amount of tissue in the paraffin blocks to perform serial sections for histochemical preparations and presenting more than 10 medium-power (100-) fields of adequate tissue for microscopic evaluation, were included in this study. 22 of these cases were etiologically classified as idiopathic (idiopathic-NSIP) and 18 cases had concomitant Systemic Sclerosis (NSIP-SSc) being 4 patients with limited cutaneous SSc and 14 with diffuse cutaneous SSc, according to American Rheumatism Association Diagnostic and Therapeutic Criteria Committee (Preliminary criteria for the classification of systemic sclerosis (scleroderma). Subcommittee for scleroderma criteria of the American Rheumatism Association Diagnostic and Therapeutic Criteria Committee, 1980) ${ }^{24 .}$

Clinical data was abstracted by retrospective chart review. The survival rates were calculated 36 months after the biopsy. Specimens with an alternative etiology (e.g., pneumoconiosis) were excluded from the analysis, as well as specimens obtained from patients with other collagen vascular diseases, biopsies showing extensive honeycomb changes (end-stage lung disease), or a dual histological pattern (2 different patterns at 2 different biopsy sites). 
Two or three biopsies per patient were sampled and the tissue specimens collected with the assistance of modern imaging techniques, i.e. High Resolution Computerized Tomography (HRCT), which usually includes normal, intermediate and more severely affected areas in different parts of the lung.

\section{Baseline data}

Time of performance of pulmonary function tests ranged from one to three months before the lung biopsy. Measurements were performed using a computerized spirometer (Collins Plus Pulmonary Function Testing System; Warren E.Collins, Inc., Braintree, MA) in accordance with the American Thoracic Society standardization ${ }^{25}$

Forced vital capacity (FVC), forced expiratory volume in one second (FEV1), the FEV1/FVC ratio, and forced expiratory flow values were obtained. Residual volume (RV) and total lung capacity (TLC) were measured by the helium dilution method with a Master Screen apparatus (Erich Jaeger GmbH, Wuerzburg, Germany), and the DLCO and DLCO/VA by the single breath-holding helium dilution method ${ }^{26}$. Lung function measurements were expressed as percentages of predicted values.

The echocardiography, as well as other cardiac parameters, were normal for both groups of patients. Neither idiopathic NSIP or SSc-NSIP patients presented pulmonary hypertension. 


\section{Pathologic review of the specimens}

Pulmonary biopsies were reviewed by three pathologists with no knowledge of the clinical diagnoses. Non specific interstitial pneumonia was characterized by temporally homogenous septal inflammatory thickening and minimal organizing fibrosis as previously described ${ }^{7}$.

Normal lung tissue was obtained from five individuals (mean age $60 \pm$ 3.6 years), who had died from traumatic causes, as a control group. None of these control subjects met any of the histologic criteria for interstitial pneumonia or an alternative pulmonary pathology.

\section{Parenchymal and vascular analysis.}

Lung parenchyma was evaluated for epithelial and endothelial cells as well as vascular activity by immunohistochemistry using the avidin-biotin immunoperoxidase complex technique. For epithelial cell expression, the antibodies used were anti-cytokeratin 7 (CK7) (Clone OV-TL 12/30; Dako, Glostrup, Denmark; 1:100 dilution), which recognizes type I and II pneumocytes and bronchial epithelial cells; surfactant apoprotein-A (SP-A) (Clone PE10; Dako, Carpinteria; CA, USA; dilution, 1:800) which recognizes type II pneumocytes and Clara cells. Vascular endothelial cells were evaluated with an anti-CD34 monoclonal antibody (Clone QBEnd/10; Novocastra Laboratories Ltd, Newcastle, United Kingdom; dilution, 1:400). The degree of endothelial activity was evaluated using VCAM-1, a rabbit polyclonal antibody against vascular cell adhesion molecule (VCAM-1)(Santa Cruz Biotecnology , Inc, Santa Cruz, Ca; dilution, 1:8000). 
Epithelial and vascular density as well as vascular activity were done by quantification of $\mathrm{CK}-7+$, Sp-A + CD34+ VCAM-1+ cells at $\mathrm{x} 400$ magnification with an eyepiece systematic point-sampling grid with 100 points and 50 lines to count the fraction of lines overlying positively stained structures ${ }^{27}$. We averaged this over ten microscopic fields to obtain a final result as a percentage of staining structures.

\section{Statistical analysis}

Mean and range values for each parameter evaluated were plotted in tables. Before proceeding to a formal analysis of data, descriptive statistics were recorded and graphically illustrated. Differences among groups were assessed by Shapiro-Wilk's tests for normality, and Levene's one-way analysis for homogeneity of variance. T-test and ANOVA with Bonferroni post-hoc test for multiple comparisons were performed when appropriate. Survival curves comparing the quantitative changes were initially tested in Kaplan-Meier univariate model. The level of significance was established at 0.05. All statistical procedures were performed with SPSS version 10.0 statistical software (SPSS, Inc., Chicago, IL). The level of significance was set at $p<0.05$.

\section{RESULTS}

\section{Clinical characteristics}

Patients with idiopathic-NSIP included 10 males and 12 females with a median age o $50.81 \pm 2.17$ years. The SSc-NSIP group was composed of 
18 females with a median age of $45.82 \pm 2.19$ years. Dyspnea was the predominant respiratory symptom in the SSc-NSIP $(n=17)$ and idiopathicNSIP ( $n=18)$ groups. Smokers were more prevalent in the idiopathic group. No differences was found between the 4 patients with limited cutaneous SSc and 14 with diffuse cutaneous SSc in terms of NSIP parameters. Additional clinical and demographic data are summarized in Table 1.

\section{Qualitative Analysis of Parenchymal and Vascular Repair/Remodeling}

Morphologic features of both groups were similar as demonstrated by examination of H\&E stained slides. Non specific interstitial pneumonia was characterized by temporally homogenous septal inflammatory thickening and minimal organizing fibrosis (Figure 1). SSc- NSIP and idiopatic-NSIP showed a diffuse, homogeneous Ck-7 (Fig. 2 A, B respectively) and Sp-A (Fig.2 C, D respectively) epithelium immunolocalization coincident with the inflammatory alveolar septal thickening visualized in H\&E slides (Figure 1). A uniform distribution of alveolar capillary endothelial cells CD34+ in SSc-NSIP (Fig. 2E) and idiopathic-NSIP (Fig. 2F) were observed. They coincided with the maintenance of the pulmonary architecture. In inflammatory septal thickening areas of SSc- NSIP capillaries appeared dilated and decreased in number (Fig. 2E) when compared to idiopathic-NSIP (Fig. 2F). A more uniform degree of endothelial cell proliferation was present in alveolar septal thickening in the idiopathic-NSIP subgroup (Fig. 2H) Endothelial cells in these areas of decreased alveolar capillary density were strongly immunoreactive with VCAM-1 (Fig. 2G) in SSc-NSIP compared to idiopathic-NSIP (Fig. 2H). 


\section{Quantitative Analysis of Parenchymal and Vascular Repair/Remodeling}

Results of the quantitative analysis are summarized in table 1. Epithelial cell density measured by CK7+ expression was lower in SSc-NSIP when compared with idiopathic-NSIP and this difference was statistically significant $(5.33 \pm 1.77$ vs $11.46 \pm 3.39 ; p<0.0001)$. However, type II pneumocytes and Clara cells measured by Sp-A expression was dramatically reduced in idiopathic-NSIP compared to SSc-NSIP, this difference being also statistically significant $(7.02 \pm 2.77$ vs $14.45 \pm 11.21 ; p=0.02)$.

A remarkable decrease in microvessel density measured by endothelial cell CD-34 expression was found in SSc-NSIP compared to idiopathic-NSIP (4.94 \pm 1.47 vs $11.69 \pm 1.47 ; p<0.0001)$. In contrast, vascular activity measured by VCAM-1 expression was higher in NSIP-SSc when compared with the idiopatic group (3.84 \pm .0 .97 vs $0.67 \pm 0.06 ; p<0.0001)$.

\section{Association between Remodeling/Repair, Functional Data and Prognosis}

During the follow up period of 36 months, two patients died; both patients had a clinical diagnosis of idiopathic-NSIP. All patients studied showed a restrictive lung function pattern characterized by a decrease in TLC [mean values in idiopathic- NSIP (63\%) and SSc-NSIP (76\%) of predicted values] and an increased $\mathrm{FEV}_{1} / \mathrm{FVC}$ ratio $\times 100$ [mean values in idiopathicNSIP (104\%) vs SSc-NSIP (97\%) of predicted values]. The mean predicted values of DLCO were decreased in both idiopathic-NSIP (43\%) and SScNSIP (53\%) patients (Table 1). A significant difference was found for DLCO/VA in idiopathic- NSIP compared to SSc-NSIP (97\% vs 59\%; 
$p<0.0001$ (Table 1). Equally significant was the direct association between vascular density and DLCO/NA $(p=0.02)$ whereas a marginal significance was found for the inverse association with TLC $(p=0.08)$. Vascular density and activity showed a significant negative association $(p<0.001)$.

No difference in prognosis was identified according to age or NSIP subgroup. Lungs with low vascular density and high vascular activity showed a trend for better prognosis but this difference did not reach statistical significance $(p=0.15$ and $p=0.06$, respectively).

\section{DISCUSSION}

When first described by Katzenstein and colleagues, NSIP was considered a descriptive term rather than a specific diagnosis ${ }^{28}$. Actually this histologic pattern can be associated with many conditions such as CVD, drug exposure, and hypersensitivity pneumonia. It has been suggested that NSIP is rather an injury pattern that can be found in many clinical settings, the idiopathic form being one of its subsets.

Our study comparing SSc-NSIP and idiopathic-NSIP focused on the repair and remodeling process between these two groups. Some investigators also believe that the groups are not comparable because they have different clinical features, but our investigation was designed to compare the well known histological pattern of NSIP and look for differences in these groups of patients. We are comparing the same histological pattern in 2 different sets of patients, and given the rarity of these diseases this was our best attempt to research the pathologic pattern in these two populations. 
The question of interest is whether additional morphological information gathered from evaluation of the parenchyma or vascular components can help us identify differences in prognosis.

The processes of regeneration, repair and remodeling comprise a series of complex, sequential steps. It has been demonstrated that, lungs of mammals can regenerate and re-grow ${ }^{29}$. After surgical resection in animal experiments an increased proliferation of epithelial, mesenchymal and endothelial cells occurs, as well as the restitution of the original lung volume ${ }^{30}$. According to the latter study the interaction between epithelial and vascular elements are thought to be important for restitution ad integrum ${ }^{31}$. It is unclear if this process also occurs in humans. In Interstitial lung disease repair and remodeling processes seem to have a major role. After injury, the alveolar epithelium initiates a wound healing process to restore its barrier integrity characterized by rapid re-epithelialization of the denuded area through epithelial cell migration, proliferation, and differentiation. The alveolar epithelium shows a marked loss of or damage to type I cells, hyperplasia of type II cells, and altered expression of adhesion molecules and major histocompatibility complex (MHC) antigens. Recruitment, proliferation of endothelial cells and fibroblasts as well as deposition of extracellular matrix leads to remodeling of the lung parenchyma ${ }^{23,31-34}$.

Comparing SSc-NSIP and idiopathic-NSIP we observed a different amount of type I and type II epithelial cells. Epithelial cell density measured by $\mathrm{Ck} 7+$ expression was considerably lower in SSc-NSIP when compared with idiopathic-NSIP, whereas type II pneumocytes and Clara cells measured 
by Sp-A + expression were reduced in idiopathic-NSIP compared to SScNSIP. These findings favor a rather more pronounced remodeling resulting from the repair process in SSc-NSIP. Conversely, in idiopathic-NSIP repair with regeneration seems to be the eventual outcome. Prior studies have shown a significant relationship between epithelial injury and idiopathic interstitial fibrosis ${ }^{18}$, while the results of our current study suggest that epithelial characterization may provide important information about restoration of lung tissue in SSc-NSIP and idiopathic-NSIP.

Differences between the patterns of vascular remodeling in lung biopsy specimens from patients with SSc-NSIP and idiopathic NSIP were noted. For example, a remarkable decrease in microvessel density measured by endothelial cells CD-34 expression was found in SSc-NSIP possibly explaining the low DLCO/VA in this group. The fibrogenic process that is so ubiquitous in scleroderma patients may partially explain these observations. There is support for this concept in the prior study by Masahito et al. whom demonstrated a decreased number of CD34-positive capillary endothelial cells in fibrotic lesions in usual idiopathic pulmonary fibrosis, while a relative increase of CD34-positive alveolar capillaries in nonfibrotic areas of the same disorder $^{35}$.

In addition, a strong, quantitative relationship was found between vascular activity measured by endothelial cells VCAM-1 expression and SScNSIP as opposed to idiopathic-NSIP. Vascular density and activity showed a significant inverse association, similar to a previous report by our group ${ }^{19}$. The VCAM-1 antigen is a membrane-associated protein that contributes to 
the extravasation of lymphocytes, monocytes, basophils, and eosinophils from the blood vessels, particularly at sites of inflammation ${ }^{36}$. As VCAM-1 immunoquantitation allows for evaluation of the degree of endothelial activity and is generally associated with inflammation, it seems that in SSc-NSIP the inflammatory component plays a greater role than fibrogenesis, and this may be why it has a better response to therapy. Our group has previously demonstrated that vascular activity progressively increases in organizing fibrotic areas of UIP (normal, collapsed, and inflammatory septal areas), whereas vascular density gradually decreased as the degree of organizing fibrosis increased and was lower than in control lungs in the most extensively fibrotic lesions (mural organizing fibrosis of UIP) ${ }^{20}$.

Restriction of lung function is more important in idiopathic interstitial pneumonias than in collagen vascular disease ${ }^{25,26}$. In our current study, similar lung function was found for both groups of NSIP, except for the significant decrease of DLCO/VA in SSc-NSIP, and its direct association with vascular density. Although not significant, this must be taken into account and related to the small number of patients included into the study.

Our study has limitations and one of them is the short clinical follow-up period (36 months) which could have failed to detect a small difference in survival between the groups and the repair and remodeling mechanisms. Unfortunately not all the patients had bronchoalveolar lavage performed. Another important information would be the duration of NSIP in SSc and nonSSc patients, even that this study was designed as a histologic study and start to follow these patients after the biopsy. It also would be interesting to 
compare histological data between patients with SSc evolving for > 5years and $<5$ years, but unfortunately our follow up was limited to $<5$ years, although these patients will continue to be followed. Further studies with more extended follow-up will be required to address these issues definitely.

In summary, we identified quantitative morphologic differences between two major subgroups of nonspecific interstitial pneumonia, i.e. SSc associated and the idiopathic form. The different forms of parenchymalvascular interactions in SSc-NSIP, by repair and remodeling, and idiopathicNSIP, by repair and regeneration, represent evolutionary adapted responses to injury, which depend at least in part on the extent of parenchymal and vascular alterations, which in the future may offer potential targets to direct the treatment of these patients.

\section{REFERENCES}

1. Jimenez SA, Derk CT: Following the molecular pathways toward an understanding of the pathogenesis of systemic sclerosis. Ann Intern Med $2004 ; 140: 37-50$.

2. White B. Interstitial lung disease in scleroderma. Rheum Dis Clin North Am 2003; 29:371-390

3. Jacobsen S, Ullman S, Shen $G Q$, et al. Influence of clinical features, serum antinuclear antibodies, and lung function on survival of patients with systemic sclerosis. J Rheumatol 2001; 28:2454-2459

4. Steen VD, Medsger TA. Severe organ involvement in systemic sclerosis with diffuse scleroderma. Arthritis Rheum 2000; 43:2437-2444 
5. Altman RD, Medsger TA, Bloch DA, et al. Predictors of survival in systemic sclerosis (scleroderma). Arthritis Rheum 1991; 34:403-413

6. Hubbard R, Venn A. The impact of coexisting connective tissue disease on survival in patients with fibrosing alveolitis. Rheumatology 2002; 41:676-679. 7.Steen VD, Conte C, Owens GR, Medsger TA Jr. Severe restrictive lung disease in systemic sclerosis. Arthritis Rheum 1997;40:1984-91.

8. American Thoracic Society/European Respiratory Society (2002) International Multidisciplinary Consensus Classification of the Interstitial Pneumonia. Am J Respir Crit Care Med 65:277-304.

9. Ito I, Nagai S, Kitaichi M, et al. Pulmonary manifestations of primary Sjogren's syndrome: a clinical, radiologic, and pathologic study. Am J Respir Crit Care Med 2005; 171:632-638.

10. Douglas WW, Tazelaar HD, Hartman TE, et al. Polymyositisdermatomyositis associated interstitial lung disease. Am J Respir Crit Care Med 2001;164:1182-1185.

11. Kim DS, Yoo B, Lee JS, Kim EK, Lim CM, Lee SD, Koh Y, Kim WS, Kim WD, Colby TV, Kitaichi M. The major histopathologic pattern of pulmonary fibrosis in scleroderma is nonspecific interstitial pneumonia. Sarcoidosis Vasc Diffuse Lung Dis 2002; 19: 121-127.

12. Bouros D, Wells AU, Nicholson AG, Colby TV, Polychronopoulos V, Pantelidis P, Haslam PL, Vassilakis DA, Black CM, du Bois RM. Histopathologic subsets of fibrosing alveolitis in patients with systemic sclerosis and their relationship to outcome. Am J Respir Crit Care Med 2002; 165: $1581-1586$. 
13. Tansey D, Wells A U, Colby T V, Ip S, Nikolakoupolou A, du Bois R M, Hansell D M \& Nicholson A G. Variations in histological patterns of interstitial pneumonia between connective tissue disorders and their relationship to prognosis. Histopathology 2004, 44, 585-596.

14. Fujita J, Yamadori I, Suemitsu T, et al. Clinical features of non-specific interstitial pneumonia. Respir Med 1999, 93:113-118.

15. White B, Moore WC, Wigley FM, et al.: Cyclophosphamide is associated with pulmonary function and survival benefit in patients with scleroderma and alveolitis.Arch Intern Med 2000, 132:947-954.

16. Felicio CHC, Parra ER, Capelozzi VLIdiopathic and Collagen Vascular Disease Nonspecific InterstitialPneumonia: Clinical Significance of Remodeling Process. Published on line in Lung Jan 2007.

17.Rozin G F, Gomes M M, Parra E R, Kairalla R A, de Carvalho C R R \& Capelozzi V L Collagen and elastic system in the remodelling process of major types of idiopathic interstitial pneumonias (IIP) 2005) Histopathology $46,413-421$.

18. Baptista AL, Parra ER, Barbas Filho JV, Kairalla RA, de Carvalho CR, Capelozzi,VL Structural Features of Epithelial Remodeling in Usual Interstitial Pneumonia Histologic Pattern Lung (2006) 184:239-244.

19. Parra ER, da Costa LRS, Ab'Saber AM, et al. Nonhomogeneous Density of CD34 and VCAM-1 Alveolar Capillaries in Major Types of Idiopathic Interstitial Pneumonia. Lung. 2005; 183; 363-373. 
20. Parra ER, Kairalla RA, de Carvalho CR, Capelozzi,VL Abnormal Deposition Of Collagen-Elastic Vascular Fibres And Prognostic Significance In Idiopathic Interstitial Pneumonias Thorax published online Jan 2007. 21. Willis BC, du Bois RM, Borok Z . Epithelial Origin of Myofibroblasts during Fibrosis in the Lung. Proc Am Thorac Soc Vol 3. pp 377-382, 2006.

22. Keane MP, Michael P. Inflamation and angiogenesis in fibrotic lung disease. Semn Resp Crit Care Med 2006: 27: 589-599.

23. Selman M, Talmadge Jr E K, Pardo A. Idiopathic Pulmonary Fibrosis: Prevailing and Evolving Hypotheses about Its Pathogenesis and Implications for Therapy Ann Intern Med. 2001;134:136-151.

24. Preliminary criteria for the classification of systemic sclerosis (scleroderma). Subcommittee for scleroderma criteria of the American Rheumatism Association Diagnostic and Therapeutic Criteria Committee. Arthritis Rheum. 1980 May;23(5):581-90.

25. American Thoracic Society. Standardization of spirometry, 1994 update. Am J Respir Crit Care Med 1995;152:1107-1136.

26. Quanjer PhH, Tammeling GJ, Cotes JE, Pedersen OF, Peslin R, Yernault J-C: Lung volumes and forced ventilatory flows. Report working party, Standardization of lung function tests, European Community for steel and coal. Official Statement of the European respiratory Society.Eur Respir J 1993, (Suppl 16):5-40.

27. Gundersen HJ, Bendtsen TF, Korbo L, et al. Some new, simples and efficient stereological methods and their use in pathological research and diagnosis. APMIS. 1988; 96; 379-394. 
28. Katzenstein AL, Fiorelli RF. Nonspecific interstitial pneumonia/fibrosis. Histologic features and clinical significance. Am J Surg Pathol 1994; 18:136-147.

29. Brown LM, Rannels SR, Rannels DE.Implications of postpneumonectomy compensatory lung growth in pulmonary physiology and disease. Respir Res. 2001;2:340-7.

30. Voswinckel R, Motejl V, Fehrenbach A, Wegmann M, Mehling T, Fehrenbach $\mathrm{H}$,Seeger $\mathrm{W}$. Characterisation of post-pneumonectomy lung growth in adult mice. Eur Respir J. 2004;24:524-32.

31.Kasper M, Haroske G. Alterations in the alveolar epithelium after injury leading to pulmonary fibrosis. Histol Histopathol. 1996;11:463-83.

32.Kawanami O, Ferrans VJ, Crystal RG. Structure of alveolar epithelial cells in patients with fibrotic lung disorders. Lab Invest. 1982;46:39-53.

33. Kasper M, Koslowski R, Luther T, Schuh D, Muller M, Wenzel KW.Immunohistochemical evidence for loss of ICAM-1 by alveolar epithelial cells in pulmonary fibrosis. Histochem Cell Biol. 1995;104:397-405.

34. Kallenberg CG, Schilizzi BM, Beaumont F, De Leij L, Poppema S, The TH. Expression of class II major histocompatibility complex antigens on alveolar epithelium in interstitial lung disease: relevance to pathogenesis of idiopathic pulmonary fibrosis. J Clin Pathol. 1987;40:725-33.

35. Masahito E, Minoru S, Naoko S, Yuichiro K, Takashi S, Mareyuki E,Hironobu S, Takashi K, Toshihiro N. Heterogeneous increase in CD34positive alveolarcapillaries in Idiopathic Pulmonary Fibrosis. Am J Respir Crit Care Med Vol 169. pp 1203-1208, 2004. 
36. Abonia JP, Hallgren J, Jones T, Shi T, Xu Y, Koni P, Flavell RA, Boyce JA, Austen KF, Gurish MF. Alpha-4 integrins and VCAM-1, but not MAdCAM1, are essential for recruitment of mast cell progenitors to the inflamed lung. Blood. 2006;108:1588-94.

37. Bevilacqua MP. Endothelial-leukocyte adhesion molecules. Annu Rev Immunol. 1993;11:767-804.

\section{Anexo 5}

Artigo originado da tese (submetido ao Histopathology).

ARTERIAL AND INTERSTITIAL REMODELING PROCESSES IN NONSPECIFIC INTERSTITIAL PNEUMONIA: SYSTEMIC SCLEROSIS VERSUS IDIOPATHIC

Erika Franco de Carvalho $\mathrm{MD}^{1}$, Edwin Roger Parra MD, $\mathrm{PhD}^{1}$, Romy de Souza MD,PhD ${ }^{1}$, Alexandre Muxfeldt $\mathrm{A}^{\prime} \mathrm{b}$ Saber ${ }^{1}, \mathrm{MD}, \mathrm{PhD}$, Juliana de Carvalho Machado, $\mathrm{MD}^{3}$, Vera Luiza Capelozzi, MD, $\mathrm{PhD}^{1}$

Departments of Pathology ${ }^{1}$ and Rheumatology ${ }^{2}$ University of Sao Paulo Medical School and Department of Internal Medicine $^{3}$ Ribeirão Preto University of São Paulo

Short Title: Systemic sclerosis versus idiopathic

\section{Corresponding author:}

Vera Luiza Capelozzi, MD, PhD our Edwin Roger Parra, MD, PhD 
Departamento de Patologia

Faculdade de Medicina da Universidade de São Paulo

Av. Dr. Arnaldo 455; ZIP CODE - 01246-903, São Paulo, SP, Brazil.

Phone - (5511)3061-7427; FAX - (5511)5096-0761

E-mail - vcapelozzi@lim05.fm.usp.br erparra20003@yahoo.com.br

This study was supported by the following Brazilian agencies: the National Council for Scientific and Technological Development [CNPq]; the Foundation for the Support of Research of the State of São Paulo [FAPESP 2000/14336-0]; and the Laboratories for Medical Research [LIM 05], Clinicas Hospital, School of Medicine, University of São Paulo.

\section{ABSTRACT}

Aims and Methods: Pulmonary biopsy specimens were examined from 40 patients, 22 with idiopathic nonspecific interstitial pneumonia (NSIP) and 18 with nonspecific interstitial pneumonia associated with systemic sclerosis (SSc). We compared the septal and vascular matrix remodeling, vascular occlusion, pulmonary function tests and survival between the two groups.

Results: The content of septal collagen and elastic fibers, as well as the elastic fibers in the vascular interstitium, were higher in the SSc group $(p=0.01, p=0.001$ and $p<0.0001$, respectively). Among pulmonary function tests the DLCO/VA was affected to a greater extent in the SSc group (59\% of the predicted value in SSc and $97 \%$ in the idiopatic group). There were no differences in the collagen content of the vascular interstitium, arterial occlusion, or survival between the two groups. 
Conclusions: Although the fibrotic process is more intense in the SSc group, it does not affect the prognosis of these patients. Because the elastotic process is higher in the SSc group, this might suggest that autoimmune inflammatory mechanisms affecting the elastic fiber system could play a greater role in the pathogenesis and pulmonary remodeling process of SSc-NSIP than in idiopathic-NSIP.

Keywords: systemic sclerosis, nonspecific interstitial pneumonia, matrix remodeling, elastic fibers, collagen fibers 


\section{INTRODUCTION}

Systemic sclerosis (SSc) is an autoimmune disorder of unknown origin, characterized by an excessive deposition of collagen and other extracellular matrix proteins on the skin and multiple internal organs, including vasculature, esophagus and lungs ${ }^{1}$. Pulmonary involvement consists most often of interstitial fibrosis, and has emerged as one of the most serious visceral complications in SSc representing an important cause of mortality in these patients ${ }^{2,3}$. Many authors have previously shown that interstitial fibrosis associated with SSc has a better prognosis than lone cryptogenic fibrosing alveolitis, alternatively termed "idiopathic pulmonary fibrosis" 4, 5 . However, most of these studies were done before the recognition of the non specific interstitial pneumonia (NSIP) pattern and the last American Thoracic Classification consensus ${ }^{6,7}$.

More recently the NSIP pattern was described as more prevalent in the collagen vascular disease (CVD) group, including SSc, than the usual interstitial pneumonia (UIP) pattern, while the opposite is true in the idiopathic form of the disorders ${ }^{8-11}$. This might partially explain why pulmonary fibrosis associated with CVD has been reported to have a better prognosis than in idiopatic groups. However, some studies have also shown that CVD-NSIP and specifically SSc-NSIP have a better prognosis than idiopathic-NSIP ${ }^{10,11}$.

Comparing similar histologic patterns, the CVD group responds better to therapy, and this may prevent progression to a more fibrotic pattern similar to that found in UIP ${ }^{12,13}$. Recently, an improvement of clinical parameters has been shown after treatment with cyclosphosphamide in patients with interstitial 
pneumonia associated with $\mathrm{SSc}^{14,15}$. In this regard, some authors have studied pathogenetic mechanisms in idiopathic and CVD associated lung fibrosis to discover factors that might relate to better treatment and prognosis. Because pulmonary involvement in SSc has a vascular and septal interstitial component, extracellular matrix remodeling of both has been thought to be different than in other disorders. Interstitial lung disease associated with SSc comprises a series of complex, sequential steps, but among these the interstitial immunoinflammatory reactions and remodeling of the extracellular matrix are thought to be important to establishment of the fibrosis ${ }^{16}$. Others have ascribed a minor role to the inflammatory component in the idiopathic form of interstitial lung disease ${ }^{16,17}$. As the pathogenesis of these two diseases seems to be different, we hypothesize that the repair mechanisms involving the collagen/elastic system also differ, leading to a diverse remodeling process. To validate the importance of collagen/elastic system changes around the vessels and along the septal interstitium and to explore the quantitative relationship between this assessment and outcome, as well as other clinical factors including pulmonary function tests (PFT), herein we studied the collagen/elastic system in the idiopathic and SSc forms of NSIP.

\section{METHODS}

\section{Patients}

From January 1979 to December 2006, 673 surgical lung biopsies were performed at the Hospital das Clinicas da Faculdade de Medicina da Universidade de São Paulo. It was unit policy that the biopsies were 
perfomed to establish a firm clinico-pathologic diagnosis allowing the patients and clinicians to take more informed decisions about therapy.

Among these cases, a total of 40 out of 82 specimens with a histological pattern of non-specific interstitial pneumonia (NSIP), unanimously reclassified according to the American Thoracic Society / European Respiratory Society consensus classification ${ }^{8}$ by two lung pathologists, with sufficient amount of tissue in the paraffin blocks to perform serial sections for histochemical preparations and presenting more than 10 medium-power (100·) fields of adequate tissue for microscopic evaluation, were included in this study. 22 of these cases were etiologically classified as idiopathic (idiopathic-NSIP) and 18 cases had concomitant Systemic Sclerosis (SSc-NSIP), being 4 patients with limited cutaneous SSc and 14 with diffuse cutaneous SSc, according to American Rheumatism Association Diagnostic and Therapeutic Criteria Committee (Preliminary criteria for the classification of systemic sclerosis (scleroderma). Subcommittee for scleroderma criteria of the American Rheumatism Association Diagnostic and Therapeutic Criteria Committee, 1980) ${ }^{18}$ Clinical data was abstracted by retrospective chart review. All the biopsies were obtained prior to initiation of any therapy. Patients of both groups have similar length of histories of respiratory symptoms.

The survival rates were calculated 36 months after the biopsy. Only specimens from cases that fulfilled these consensus criteria were included. We excluded specimens of any other possible etiology (e.g., pneumoconiosis) and/or with histological features suggestive of an alternative diagnosis (e.g., 
eosinophilic pneumonia). We also excluded biopsy specimens obtained from patients with other collagen vascular diseases, extensive honeycomb changes (end-stage lung disease), a dual histological pattern (2 different patterns at 2 different biopsy sites), and/or morphologic features not consistent with a specific histological pattern. History of smoking was present in 5 patients, being 1 with SSc-NSIP and 4 with idiopathic-NSIP. Two or three biopsies per patient were sampled and the tissue specimens collected with the assistance of modern imaging techniques, i.e. High Resolution Computerized Tomography (HRCT), which usually includes normal, intermediate and more severely affected areas in different parts of the lung. The study was approved by the local Ethics Committee.

\section{Baseline data}

The pulmonary function tests were completed one to three months before the lung biopsy. Measurements were performed using a computerized spirometer (Collins Plus Pulmonary Function Testing System; Warren E.Collins, Inc., Braintree, MA) in accordance with the American Thoracic Society standardization ${ }^{19}$. Forced vital capacity $(\mathrm{FVC})$, forced expiratory volume in one second (FEV1), the FEV1/FVC ratio, and forced expiratory flow values were obtained. Residual volume (RV) and total lung capacity (TLC) were measured by the helium dilution method with a Master Screen apparatus (Erich Jaeger GmbH, Wuerzburg, Germany), and the DLCO and DLCO/VA by the single breath-holding helium dilution method ${ }^{20}$. Lung function measurements were expressed as percentages of predicted values. 
The echocardiography, as well as other cardiac parameters, were normal for both groups of patients. Neither idiopathic-NSIP or SSc-NSIP patients presented pulmonary hypertension.

\section{Histopathologic classification}

Pulmonary specimens were reviewed by three pathologists blinded to their clinical features. Nonspecific interstitial pneumonia was characterized by the temporally homogeneous septal fibrotic thickening and minimal inflammatory process, characterizing the fibrotic pattern of $\mathrm{NSIP}^{7}$. The vessels from each specimen were initially evaluated by semiquantitative analysis for different levels of arterial occlusion in vessels within the different areas of fibrosis using a grading system as follows: grade I- isolated hypertrophy of the arterial media, grade II- proliferative intimal lesions, grade III- total occlusion of arterial lumen by fibrous tissue, grade IV- plexiform lesions ${ }^{21}$.

Normal lung tissues from non-pneumonic and non-emphysematous areas were obtained from five individuals (mean age $60 \pm 3.6$ years), who had died from traumatic causes, as a control group. None of these control subjects met any of the histologic criteria for interstitial pneumonia.

\section{Collagen-Elastic Fiber Analysis}

Collagen/elastic fibers were characterized by histochemical staining. Collagen fiber characterization was performed using $0.2 \%$ solution of Sirius red (Direct Red 80, C. I. 35780, Aldrich, Milwaukee, WI 53233, USA) 
dissolved in aqueous saturated picric acid. This dye has been used for staining collagen in histologic specimens and was demonstrated to also enable quantitative analysis of collagen in paraffin sections ${ }^{22}$. The enhancement of collagen birefringence promoted by the Picrosiriuspolarization method is specific for collagenous structures composed of aggregates of oriented molecules. Elastic fibers were characterized by the Weigert's Resorcin-Fuchsin method, after previous oxidation ${ }^{22}$.

Septal interstitium. The quantification of collagen/elastic fibers in septal interstitium was performed by an image analysis system; the system consists of a JVC TK-C1380 camera applied to a Leica microscope, from where the images were sent to a monitor (Trinitron Sony). By means of a digitising system (Oculus TCX, Coreco inc; St Laurent, Quebec, Canada) inserted in a computer (Pentium3 300Mhz), the images were processed by a software (Image ProPlus). A total of 10 fields of each biopsy were analyzed at a magnification of $x 400$. The number of fields examined was previously validated in order to confirm the result calculating a running mean for the results obtained and using the minimun number of fields to ensure the mean varies by less than $10 \%$. The thresholds for fibers of the collagenous and elastic systems were established for each slide, after enhancing the contrast up to a point at which the fibers were easily identified as black (elastic) or birefringent (collagen) bands. The area occupied by the fibers was determined by digital densitometric recognition, by adjusting the threshold level of measurement up to the gray density of the fibers of the collagenous and elastic systems. To avoid bias secondary to septal edema or to alveolar 
collapse, the total alveolar solid area of each field was also measured. With these two measures, the ratio of the fiber area in relation to the solid tissue of that field was obtained. The results expressed the amount of fibres of the collagen and elastic types (in area) per total area of interstitial wall expressed in percent.

Vascular interstitium. The collagen of the medial layer and elastic fiber content of the pre-acinar arteries (mean of 8 per case, with mean diameter from 19,67 to $28.94 \mu \mathrm{m}$ ) were measured following the same system and principles described above. The vascular wall measurements were expressed as a relation between the quantity of collagen and elastic fibers divided by the total vascular area studied. The vascular area of each artery analysed was carefully measured in the image analysis system using a cursor that allows the free determination of the area from the basement membrane to the external elastic membrane. The results express the amount of fibers of the collagenous and elastic systems (in area) per total area of vascular wall expressed in percentage.

\section{Statistical analysis}

Mean and range values for each parameter evaluated were plotted in tables. Before proceeding to a formal analysis of data, descriptive statistics were recorded and graphically illustrated. Differences among groups were assessed by Shapiro-Wilk's tests for normality, and Levene's one-way analysis for homogeneity of variance. T-test and ANOVA with Bonferroni post-hoc test for multiple comparisons were performed when appropriate. 
Survival curves comparing the quantitative changes of the collagen and elastic fibres in septal and vascular interstitium in SSc-NSIP and idiopathicNSIP were tested in a Kaplan-Meier univariate model. All statistical procedures were performed with SPSS version 10.0 statistical software (SPSS, Inc., Chicago, IL). The level of significance was set at $p \leq 0.05$.

\section{RESULTS}

\section{Clinical characteristics}

Median age of patients with idiopathic-NSIP (10 males and 12 females) was $50.81 \pm 2.17$ years, and $45.82 \pm 2.19$ years for the SSc-NSIP group (18 females). Dyspnea at presentation was noted in 17 and 18 patients in the SSc-NSIP groups and idiopathic-NSIP respectively. Smokers were more prevalent in the idiopathic group. Additional clinical and demographic data are summarized in Table 1.

\section{Qualitative Analysis of Parenchymal and Vascular Repair/Remodeling}

The morphologic aspect between the two groups did not differ using the H\&E, Weigert's resorcin-fuchsin, and picrosirius polarized (Fig. 1). Both NSIP groups showed temporally homogeneous septal fibrotic thickening and minimal inflammatory process and the maintenance of the septal architecture (Fig 1A). Alterations of the elastic system were present with disruption and proliferation of the fibers (Fig. 1B). NSIPs lungs showed a red-orange birefringence in the inflammatory septal thickening with minimal fibrosis and the maintenance of the septal architecture (Fig. 1C). The morphology of the 
pre-acinar arteries appeared similar, although in the SSc-NSIP a rather specific 'onion skin' pattern of vascular occlusion as well as the more fibrosis were present. We could observe 3 different degree of arterial occlusion. Grade I (Fig. 1D), grade II (Fig. 1G), grade III (Fig. 1J). A major proliferation of elastic fibres in the internal and external elastic lamina of artery wall in NSIPs lungs was observed, in relation to different degrees of arterial occlusion: grade I (Fig. 1E), grade II (Fig. 1H) and grade III (Fig. 1K). Distortion of artery wall architecture and increase of birefringence in arterial layers in three different degrees of arterial occlusion were seen: grade I (Fig. 1F), grade II (Fig. 1I) and grade III (Fig. 1L).

\section{Quantitative Analysis of Parenchymal and Vascular Repair/Remodeling}

Although there were no obvious qualitative differences between the two groups of NSIP, important measurable quantitative variables were noted (Table 1). The density of collagen fibers in the septal interstitium was significantly higher in SSc- NSIP when compared with idiopathic-NSIP and this difference was statistically significant $(29.9 \pm 17.10$ vs $14.46 \pm 2.58$, $p=0.01)$. There was a trend for increase in the density of collagen in the vascular wall in SSc-NSIP when compared to idiopathic-NSIP, but this difference did not achieve statistical significance (31.46 \pm 21.41 vs $3.85 \pm$ 0.82, $p=0.26$ ). Comparing the elastic fiber density along septal interstitium a significant increase was found in SSc-NSIP compared to idiopathic-NSIP $(12.72 \pm 4,02$ vs $7.26 \pm 2.70, p=0.001)$. Similar findings were noted with elastic fiber density in the vascular wall when comparing SSc-NSIP and 
idiopathic-NSIP (41.68 \pm 11.20 vs $25.50 \pm 3.20, p<0.0001)$. No differences were found in vascular grading between the NSIP groups.

\section{Association Between Remodeling/Repair to Functional Data and Prognosis}

All patients studied presented a restrictive lung function pattern characterized by a decrease in TLC [mean values in idiopathic- NSIP (63.25\%) and SSc-NSIP (76.44\%) of predicted values] and an increase in $\mathrm{FEV}_{1} / \mathrm{FVC}$ ratio $\times 100$ [mean values in idiopathic-NSIP $(104.45 \%)$ vs SScNSIP $(69.56 \%)$ of predicted values]. The mean predicted values of DLCO were decreased in both idiopathic-NSIP (43\%) and SSc-NSIP (53.9\%) patients (Table 1). A significant difference was found for DLCO/VA in idiopathic-NSIP compared to SSc-NSIP (97\% vs 59.44\%; $p<0.0001$ (Table 1). Equally significant was the inverse association between vascular collagen fibers density and ERV $(p=0.007)$ as well as vascular grade and VR $(p=0.003)$. Conversely, a direct association was found between elastic fiber density and vascular grade $(p=0.001)$.

After a follow-up of 36 months, two patients in the idiopathic-NSIP group died (6 and 10 months after biopsy), while all patients in the SSc-NSIP group were still alive. No statistically significant difference in prognosis was found for age, physiologic tests, NSIP groups and collagen-elastic system remodeling. 


\section{DISCUSSION}

The process of vascular and septal extracellular matrix remodeling is a dynamic process that involves changes in collagen and elastic fiber systems resulting in different degrees of vascular occlusion and septal thickening ${ }^{23,24}$. Collagen fibers are distributed diffusely throughout the septal and periadvential interstitium being synthesized by fibroblasts, myofibroblasts, and smooth-muscle cells and providing tensile strength to parenchyma and the vessel wall ${ }^{25}$. Elastic fibers provide recoil tension to restore the parenchyma to its previous configuration after the stimulus for inspiration has ceased ${ }^{26}$. In normal alveolar septa, a subepithelial layer of elastic fibers, composed mainly of fully mature ones, is responsible for this property. Furthermore, in normal elastic arteries, the internal and external elastic laminas are also composed mainly of fully mature elastic fibers that confer a great deal of elasticity to the vascular tissue under normal circumstances ${ }^{27,28}$. Due to their mechanical properties, elastic fibers provide the elasticity needed for good vascular function ${ }^{27,28}$.

The results of our study show that even though vascular and septal interstitium remodeling might be qualitatively similar in SSc-NSIP and idiopathic-NSIP, they are quantitatively different. For example, we found that elastic fiber density along the septal interstitium was significantly increased in SSc-NSIP compared to idiopathic-NSIP, the same occurring with elastic fiber density around the vascular interstitium. We did find a direct association between elastosis and vascular grade. The elastosis process found probably occurs after elastin destruction $^{29}$. Its destruction takes place in certain 
pathologic conditions due to the release of powerful elastolytic proteases by inflammatory cells ${ }^{30,31}$. Reactivation of elastin synthesis is observed in response to the increased destruction, but in a highly disordered manner with deleterious consequences to the mechanical properties of the lung. It contributes to the loss of normal alveolar architecture, resulting in a tendency for collapse and an impaired mechanism of inflammatory resolution ${ }^{31-33}$. Recent studies suggest that elastin gene expression is increased following injury in certain animal models ${ }^{32-35}$. The elastotic process seems to be related to a response to inflammatory injury. Also collagenase and neutrophil elastase have been shown in patients with SSc submitted to bronchoalveolar lavage $(B A L)^{36,37}$. All of these findings support the idea that the increase on elastic fibres found in our study may not be the result of a longer standing chronic condition because the patients of both groups included in our study had similar length of respiratory symptoms. They also explain why the SSc have more collagen and elastic fibres than the idiopathic group - and if this is the case what is expanding the alveloar septae in the latter patients? In SSc-NSIP the activity of the disease is characterized by repeated occurrence of inflammation and reparation with increased fibroelastosis. In idiopathic-NSIP the disease is more indolent with constant and basal inflammatory activation leading to a more homogeneous reparative process. As previously reported by our group, the fibroelastotic process in septal and vascular wall in idiopathic-NSIP may be the result of a direct extracellular matrix remodeling after diffuse epithelial damage that eventually and focally can overwhelm the epithelial regenerative capacity, provoking basement membrane disruptions ${ }^{21,23,25}$. 
In our study, we also found an increased density of collagen fibers in the septal interstitium in SSc- NSIP when compared with idiopathic-NSIP, as well as a trend for an increase in the density of collagen in the vascular wall in SSc-NSIP. The clinical significance of these findings remains uncertain at the present time; some reports state that the SSc-NSIP has a better prognosis and a better response to therapy while others affirm that they do not differ in terms of prognosis ${ }^{38-39}$. As the extent of fibrosis has been related to a worse prognosis in interstitial lung disease ${ }^{40-41}$, it seems that the contribution of fibrosis to clinical outcome is different in both NSIP forms. We postulate that the structural characteristics of the fibrosis components may vary and be responsible for a more benign clinical course in the SSc group. In fact, only $15 \%$ of the latter eventually reach severe end-stage lung fibrosis $^{2}$. Usually, dense fibrosis with collagen deposition in areas of lung remodeling has been demonstrated to be an important morphological determinant of prognosis in interstitial lung disease ${ }^{41-42}$. During the limited follow-up period of 36 months, two deaths occurred in the idiopathic-NSIP group, but no difference in prognosis was found with age, sex or NSIP groups as previously described by other investigators ${ }^{38-39}$. Nevertheless, we found a significant lower DLCO/NA in SSc-NSIP patients. All patients included in this study presented a restrictive lung function pattern characterized by a similar decrease in TLC and DLCO and a similar increase in $\mathrm{FEV}_{1} / \mathrm{FVC}$ ratio. We also found an indirect association between vascular collagen fiber density and expiratory residual volume (ERV) as well as vascular grade and residual volume (RV). 
Our study has limitations and one of them is the short clinical follow-up period (36 months) which could have failed to detect a small difference in survival between the groups and the repair and remodeling mechanisms. Unfortunately not all the patients had bronchoalveolar lavage performed. Another important information would be the duration of NSIP in SSc and nonSSc patients, even that this study was designed as a histologic study and start to follow these patients after the biopsy. It also would be interesting to compare histological data between patients with SSc evolving for > 5years and $<5$ years, but unfortunately our follow up was limited to $<5$ years, although these patients will continue to be followed.

In conclusion, regardless of the pathogenetic mechanism, both forms of NSIP acquire vascular and septal fibroelastotic components that differ quantitatively, and may eventually provide important information for future treatment protocols. To confirm these findings will require larger studies, as well as prospective trials with more extended follow-up, which will be valuable to validate our results as well as to extend them to other CVD and interstitial lung diseases.

\section{References}

1. Jimenez SA, Derk CT. Following the molecular pathways toward an understanding of the pathogenesis of systemic sclerosis. Ann Intern Med 2004; 140(1):37-50.

2. Basu D, Reveille JD. Anti-scl-70. Autoimmunity 2005, 38(1):65-72. 
3. Steen VD, Conte C, Owens GR, Medsger TA Jr. Severe restrictive lung disease in systemic sclerosis. Arthritis Rheum 1997; 40 (9):1984-91.C

4. Wells AU, Hansell DM, Rubens MB, Cailes J, Black CM, du Bois RM. Functional impairment in lone cryptogenic fibrosing alveolitis and fibrosing alveolitis associated with systemic sclerosis: a comparison. Am J Respir Crit Care Med 1997;156(5):1657-1664.

5. Wells AU, Cullinan P, Hansell DM, Rubens MB, Black CM, NewmanTaylor AJ, et al. Fibrosing alveolitis associated with systemic sclerosis has a better prognosis than lone cryptogenic fibrosing alveolitis. Am $\mathrm{J}$ Respir Crit Care Med 1994;149(6):1583-1590.

6. Katzenstein AL, Fiorelli RF. Nonspecific interstitial pneumonia/fibrosis. Histologic features and clinical significance. Am J Surg Pathol 1994; 18(2): 136-147.

7. American Thoracic Society/European Respiratory Society (2001) International Multidisciplinary Consensus Classification of the Interstitial Pneumonia. Am J Respir Crit Care Med 2002; 65(3): 277-304.

8. Ito I, Nagai S, Kitaichi M, Kitaichi M, Nicholson AG, Johkoh T, Noma S, et al. Pulmonary manifestations of primary Sjogren's syndrome: a clinical, radiologic, and pathologic study. Am J Respir Crit Care Med 2005; 171(6):632-638.

9. Douglas WW, Tazelaar HD, Hartman TE, Hartman RP, Decker PA, Schroeder DR, et al. Polymyositis-dermatomyositis associated interstitial lung disease. Am J Respir Crit Care Med 2001; 164(7):1182-1185. 
10. Kim DS, Yoo B, Lee JS, Kim EK, Lim CM, Lee SD, et al. The major histopathologic pattern of pulmonary fibrosis in scleroderma is nonspecific interstitial pneumonia. Sarcoidosis Vasc Diffuse Lung Dis 2002; 19(2): 121-127.

11. Bouros D, Wells AU, Nicholson AG, Colby TV, Polychronopoulos V, Pantelidis $\mathrm{P}$, et al. Histopathologic subsets of fibrosing alveolitis in patients with systemic sclerosis and their relationship to outcome. Am J Respir Crit Care Med 2002; 165(12): 1581-1586.

12. Fujita J, Yamadori I, Bandoh S, Mizobuchi K, Suemitsu I, Nakamura Y, et al. Clinical features of non-specific interstitial pneumonia. Intern. Med. 2000; 93(5):407-411.

13. White B, Moore WC, Wigley FM, Xiao HQ, Wise RA. Cyclophosphamide is associated with pulmonary function and survival benefit in patients with scleroderma and alveolitis. Arch Intern Med 2000; 132 (12): 947-954.

14. Latsi PI, Wells AU. Evaluation and management of alveolitis and interstitial lung disease in scleroderma. Curr Opin Rheumatol 2003;15(6):748-55.

15. Tashkin DP, Elashoff R, Clements PJ, Goldin J, Roth MD, Furst DE, et al. Cyclophosphamide versus placebo in scleroderma lung disease. $\mathrm{N}$ Engl J Med 2006;354(25):2655-2666

16. Steen VD. The lung in systemic sclerosis. J Clin Rheumatol 2005; 11(1): $40-46$.

17. Fietta AM, Bardoni AM, Salvini R, Passadore I, Morosini M, Cavagna L, et al. Analysis of bronchoalveolar lavage fluid proteome from systemic 
sclerosis patients with or without functional, clinical and radiological signs of lung fibrosis. Arthritis Research \& Therapy. 2006; 8(6): R160.

18. Preliminary criteria for the classification of systemic sclerosis (scleroderma). Subcommittee for scleroderma criteria of the American Rheumatism Association Diagnostic and Therapeutic Criteria Committee. Arthritis Rheum. 1980;23 (5):581-90.

19. American Thoracic Society. Standardization of spirometry, 1994 update. Am J Respir Crit Care Med. 1995;152(3):1107-1136.

20. Quanjer PhH, Tammeling GJ, Cotes JE, Pedersen OF, Peslin R, Yernault J-C. Lung volumes and forced ventilatory flows. Report working party, Standardization of lung function tests, European Community for steel and coal. Official Statement of the European respiratory Society.Eur Respir J 1993; (Suppl 16):5-40.

21. Parra ER, Kairalla RA, de Carvalho CR, Capelozzi,VL Abnormal Deposition Of Collagen-Elastic Vascular Fibres And Prognostic Significance In Idiopathic Interstitial Pneumonias. Thorax. 2007; 62(5): 428-37.

22. Montes GS. Structural biology of the fibers of the collagenous and elastic systems. Cell Biol Intermed. 1996; 20(1); 15-27.

23. Felicio CHC, Parra ER, Capelozzi VL. Idiopathic and Collagen Vascular Disease Nonspecific Interstitial Pneumonia: Clinical Significance of Remodeling Process. Lung. 2007;185(1):39-46.

24. Rozin G F, Gomes MM, Parra ER, Kairalla RA, de Carvalho CRR, Capelozzi VL. Collagen and elastic system in the remodelling process of 
major types of idiopathic interstitial pneumonias (IIP). Histopathology. 2005; 46(4): 413-421.

25. Tozzi CA, Christiansen DL, Poiani GJ, Riley DJ. Excess collagen in hypertensive pulmonary arteries decreases vascular distensibility. Am J Respir Crit Care Med. 1994; 149 (5): 1317-26.

26. Mercer RR, Crapo JD. Spatial distribution of collagen and elastin fibers in the lungs. J. Appl. Physiol. 1990; 69(5): 756-765.

27. Karnik SK, Brooke BS, Bayes-Genis A, Sorensen L, Wythe JD, Schwartz RS, et al. A critical role for elastin signaling in vascular morphogenesis and disease. Development 2003; 130(2): 411 - 423.

28. Li DY. Brooke B, Davis EC, Mecham RP, Sorensen LK, Boak BB, et al. Elastin is an essential determinant of arterial morphogenesis. Nature 1998; 393(6682):276-280.

29. Starcher B C. Lung Elastin and Matrix. Chest 2000;117(1);229-234

30. Fukuda $Y$, Basset $F$, Soler P, Ferrans VJ, Masugi $Y$, Crystal RG. Intraluminal fibrosis and elastic fiber degradation lead to lung remodeling in pulmonary Langerhans cell granulomatosis (histiocytosis X). Am. J. Pathol. 1990; 137(2): 415-424.

31. Fukuda Y, Ferrans VJ. Pulmonary elastic fiber degradation in paraquat toxicity. An electron microscopic immunohistochemical study. J. Submicrosc. Cytol. Pathol. 1988; 20(1): 15-23. 
8. Referências 
1. Jimenez SA, Derk CT: Following the molecular pathways toward an understanding of the pathogenesis of systemic sclerosis. Ann Intern Med 2004; 140:37-50.

2. Tamby MC, Chanseaud $Y$, Guillevin L, Mouthon L. New insights into the pathogenesis of systemic sclerosis.

3. Arnett FC, Cho M, Chatterjee S, Aguilar MB, Reveille JD, Mayes MD. Familial occurrence frequencies and three United States cohorts. Arthritis Rheum 2001;44:1359-62.

4. Kahaleh, M.B. 2004. Raynaud phenomenon and the vascular disease in scleroderma. Curr. Opin. Rheumatol. 16:718-722.

5. Varga J, Abraham D.Systemic sclerosis: a prototypic multisystem fibrotic disorder. J Clin Invest. 2007 Mar;117(3):557-67.

6. Cerinic, M.M., et al. 2003. Blood coagulation, fibrinolysis, and markers of endothelial dysfunction in systemic sclerosis. Semin. Arthritis Rheum.32:285-295.

7. White B. Interstitial lung disease in scleroderma. Rheum Dis Clin North Am 2003; 29:371-390 
8. Jacobsen $S$, Ullman $S$, Shen $G Q$, et al. Influence of clinical features, serum antinuclear antibodies, and lung function on survival of patients with systemic sclerosis. J Rheumatol 2001; 28:2454-2459

9. Steen VD, Medsger TA. Severe organ involvement in systemic sclerosis with diffuse scleroderma. Arthritis Rheum 2000; 43:2437-2444

10. Altman RD, Medsger TA, Bloch DA, et al. Predictors of survival in systemic sclerosis (scleroderma). Arthritis Rheum 1991; 34:403-413

11. Hubbard R, Venn A. The impact of coexisting connective tissue disease on survival in patients with fibrosing alveolitis. Rheumatology 2002; 41:676-679.

12. Steen VD, Conte C, Owens GR, Medsger TA Jr. Severe restrictive lung disease in systemic sclerosis. Arthritis Rheum 1997;40:1984-91.

13. Dunsmore SE, Rannels DE. Extracellular matrix biology in the lung. Am. J. Physiol. 270 (Lung Cell. Mol. Physiol. 14):1996, 3-27.

14. Leslie OK, Wick Mr. Chronic diffusenlung disease. In: Practical Pulmonary pathology. 1a. Ed. Elsevier, 2005 cap 7, p. 182-195

15. Travis W D, Colby TV, Koss MN, Rosado-de-Christenson ML, Müller NL, King Jr. TE. Idiopathic Interstitial Pneumonia and Other Difuse Parenchymal Lung Diseases. In: Non-Neoplastic Disorders of the lower respiratory tract. 1a. Ed. Washington. AFIP/ARP, 2003. cap. 3, p. 49-115.

16. Liebow AA. Definition and classification of interstitial pneumonias in human pathology. Prog Respir Research 1975;8:1-33 
17. Katzenstein AL, Fiorelli RF. Nonspecific interstitial pneumonia/fibrosis. Histologic features and clinical significance. Am J Surg Pathol 1994; 18 : 136-147.

18. American Thoracic Society/European Respiratory Society (2002) International Multidisciplinary Consensus Classification of the Interstitial Pneumonia. Am J Respir Crit Care Med 65:277-304.

19. Katzenstein $\mathrm{AL}$, Idiopathic Interstitial Pneumonia In: Katzenstein and Askins Surgical Pathology of Non-Neoplastic Lung Disease. 4a. Ed. Elsevier 2006. Cap 3. pg 51-78

20. Wells AU, Hansell DM, Rubens MB, Cailes J, Black CM, du Bois RM. Functional impairment in lone cryptogenic fibrosing alveolitis and fibrosing alveolitis associated with systemic sclerosis: a comparison. Am J Respir Crit Care Med 1997;156:1657-1664.

21. Wells AU, Cullinan $P$, Hansell DM, Rubens MB, Black CM, NewmanTaylor AJ, du Bois RM. Fibrosing alveolitis associated with systemic sclerosis has a better prognosis than lone cryptogenic fibrosing alveolitis. Am J Respir Crit Care Med 1994;149:1583-1590

22. Ito I, Nagai S, Kitaichi M, et al. Pulmonary manifestations of primary Sjogren's syndrome: a clinical, radiologic, and pathologic study. Am J Respir Crit Care Med 2005; 171:632-638.

23. Douglas WW, Tazelaar HD, Hartman TE, et al. Polymyositisdermatomyositis associated interstitial lung disease. Am J Respir Crit Care Med 2001;164:1182-1185. 
24. Kim DS, Yoo B, Lee JS, Kim EK, Lim CM, Lee SD, Koh Y, Kim WS, Kim WD, Colby TV, Kitaichi M. The major histopathologic pattern of pulmonary fibrosis in scleroderma is nonspecific interstitial pneumonia. Sarcoidosis Vasc Diffuse Lung Dis 2002; 19: 121-127.

25. Bouros D, Wells AU, Nicholson AG, Colby TV, Polychronopoulos V, Pantelidis P, Haslam PL, Vassilakis DA, Black CM, du Bois RM. Histopathologic subsets of fibrosing alveolitis in patients with systemic sclerosis and their relationship to outcome. Am J Respir Crit Care Med 2002; 165: 1581-1586.

26. Tansey D, Wells A U, Colby T V, Ip S, Nikolakoupolou A, du Bois R M, Hansell D M \& Nicholson A G. Variations in histological patterns of interstitial pneumonia between connective tissue disorders and their relationship to prognosis. Histopathology 2004, 44, 585-596

27. Strieter RM. Mechanisms of pulmonary fribrosis: conference summary. Chest.2001:120(1 suppl),77S-85S.

28. Razzaque MS, Taguchi T. Pulmonary fibrosis: Cellular and molecular events. Pathology International. 2003; 53(3), 133-145.

29. Fietta AM Bardoni AM, Salvini R, Passadore I, Morosini M, Cavagna L, Codullo L Pozzi E, Meloni F, Montecucco C. Analysis of bronchoalveolar lavage fluid proteome from systemic sclerosis patients with or without functional, clinical and radiological signs of lung fibrosis. Arthritis Research \& Therapy 2006, 8:R160.

30. Steen VD: The lung in systemic sclerosis. J Clin Rheumatol 2005, 11:40-46. 
31. Thomas A. Wynn Common and unique mechanisms regulate fibrosis in various fibroproliferative diseases The Journal of Clinical Investigation Vol 117 Number 3 March 2007

32. Preliminary criteria for the classification of systemic sclerosis (scleroderma). Subcommittee for scleroderma criteria of the American Rheumatism Association Diagnostic and Therapeutic Criteria Committee. Arthritis Rheum. 1980 May;23(5):581-90.

33. American Thoracic Society. Standardization of spirometry, 1994 update. Am J Respir Crit Care Med 1995;152:1107-1136.

34. Quanjer PhH, Tammeling GJ, Cotes JE, Pedersen OF, Peslin R, Yernault J-C: Lung volumes and forced ventilatory flows. Report working party, Standardization of lung function tests, European Community for steel and coal. Official Statement of the European respiratory Society.Eur Respir J 1993, (Suppl 16):5-40.

35. Heath D, Edwards JE. The pathology of hypertension pulmonary vascular disease. A description of six grades of structural changes in the pulmonary arteries with special reference to congenital cardiac defects. Circulation 1958; 18:533-547

36. Gundersen HJ, Bendtsen TF, Korbo L, et al. Some new, simples and efficient stereological methods and their use in pathological research and diagnosis. APMIS. 1988; 96; 379-394.

37. Montes GS. Structural biology of the fibers of the collagenous and elastic systems. Cell Biol Intermed. 1996; 20; 15-27). 
38. Brown LM, Rannels SR, Rannels DE.Implications of postpneumonectomy compensatory lung growth in pulmonary physiology and disease. Respir Res. 2001;2:340-7.

39. Voswinckel R, Motejl V, Fehrenbach A, Wegmann M, Mehling T, Fehrenbach $\mathrm{H}$,Seeger W. Characterisation of post-pneumonectomy lung growth in adult mice. Eur Respir J. 2004;24:524-32.

40. Kasper M, Haroske G. Alterations in the alveolar epithelium after injury leading to pulmonary fibrosis. Histol Histopathol. 1996;11:463-83.

41. Kawanami O, Ferrans VJ, Crystal RG. Structure of alveolar epithelial cells in patients with fibrotic lung disorders. Lab Invest. 1982;46:39-53.

42. Kasper M, Koslowski R, Luther T, Schuh D, Muller M, Wenzel KW.Immunohistochemical evidence for loss of ICAM-1 by alveolar epithelial cells in pulmonary fibrosis. Histochem Cell Biol. 1995;104:397405.

43. Kallenberg CG, Schilizzi BM, Beaumont F, De Leij L, Poppema S, The TH. Expression of class II major histocompatibility complex antigens on alveolar epithelium in interstitial lung disease: relevance to pathogenesis of idiopathic pulmonary fibrosis. J Clin Pathol. 1987;40:725-33.

44. Selman M, Talmadge Jr E K, Pardo A. Idiopathic Pulmonary Fibrosis: Prevailing and Evolving Hypotheses about Its Pathogenesis and Implications for Therapy Ann Intern Med. 2001;134:136-151

45. Felicio CHC, Parra ER, Capelozzi VL. Idiopathic and Collagen Vascular Disease Nonspecific Interstitial Pneumonia: Clinical Significance of Remodeling Process. Lung. 2007 Jan-Feb;185(1):39-46. 
46. Rozin G F, Gomes M M, Parra E R, Kairalla R A, de Carvalho C R R \& Capelozzi V L Collagen and elastic system in the remodelling process of major types of idiopathic interstitial pneumonias (IIP) 2005) Histopathology 46, 413-421

47. Tozzi CA, Christiansen DL, Poiani GJ, Riley DJ. Excess collagen in hypertensive pulmonary arteries decreases vascular distensibility. Am J Respir Crit Care Med 1994; 149 (5): 1317-26

48. Mercer RR, Crapo JD. Spatial distribution of collagen and elastin fibers in the lungs. J. Appl. Physiol. 1990; 69; 756-765.

49. Karnik SK, Brooke BS, Bayes-Genis A, et al. A critical role for elastin signaling in vascular morphogenesis and disease. Development 2003; 130(2): $411-423$

50. LiDY. Elastin is an essential determinant of arterial morphogenesis. Nature 1998.393:276-280.

51. Baptista AL, Parra ER, Barbas Filho JV, Kairalla RA, de Carvalho CR, Capelozzi,VL Structural Features of Epithelial Remodeling in Usual Interstitial Pneumonia Histologic Pattern Lung (2006) 184:239-244

52. Parra ER, da Costa LRS, Ab'Saber AM, et al. Nonhomogeneous Density of CD34 and VCAM-1 Alveolar Capillaries in Major Types of Idiopathic Interstitial Pneumonia. Lung. 2005; 183; 363-373).

53. Masahito E, Minoru S, Naoko S, Yuichiro K, Takashi S, Mareyuki E,Hironobu S, Takashi K, Toshihiro N. Heterogeneous increase in CD34-positive alveolarcapillaries in Idiopathic Pulmonary Fibrosis. Am J Respir Crit Care Med Vol 169. pp 1203-1208, 2004. 
54. Kuwana, M., Okazaki, Y., Yasuoka, H., Kawakami, Y., and Ikeda, Y. 2004. Defective vasculogenesis in systemic sclerosis. Lancet. 364:603-610.

55. Del Papa, N.D., et al. 2006. Bone marrow endothelial progenitors are defective in systemic sclerosis. Arthritis Rheum. 54:2605-2615.

56. Abonia JP, Hallgren J, Jones T, Shi T, Xu Y, Koni P, Flavell RA, Boyce JA, Austen KF, Gurish MF. Alpha-4 integrins and VCAM-1, but not MAdCAM-1, are essential for recruitment of mast cell progenitors to the inflamed lung. Blood. 2006;108:1588-94.

57. Mariani TJ, Crouch E, Roby JD, Starcher B, Pierce RA. Increased elastin production in experimental granulomatous lung disease.Am. J. Pathol. 1995; 147; 988-1000 Mariani TJ, Crouch E, Roby JD, Starcher B, Pierce RA. Increased elastin production in experimental granulomatous lung disease.Am. J. Pathol. 1995; 147; 988-1000

58. Raghow R, Lurie S, Seyer JM, Kang AH. Profiles of steady state levels of messenger RNAs coding for type I procollagen, elastin, nd fibronectin in hamster lungs undergoing bleomycin-induced interstitial pulmonary fibrosis. J. Clin. Invest. 1985; 76; 1733-1739

59. Pierce RA, Albertine KH, Starcher BC, Bohnsack JF, Carlton DP, Bland RD. Chronic lung injury in preterm lambs: disordered pulmonary elastin deposition. Am. J. Physiol. 1997; 272; L452-L460.

60. Leick-Maldonado $E$ A, Lemos $M$, Tibério I $F$ LC, et al. Differential distribution of elasticsystem fibers in control and bronchoconstricted intraparenchymatous airways in the guinea-pig lung. J Submicrosc Cytol Pathol 1997; 29 (4): 427-434. 
61. Konig G, Luderschmidt C, Hammer C, Adelmann- Grill BC, BraunFalco O, Fruhmann G. Lung involvement in scleroderma. Chest 1984; 85:318-324.

62. Sibille Y, Martinot JB, Polomski LL, et al. Phagocyte enzymes in bronchoalveolar lavage from patients with pulmonary sarcoidosis and collagen vascular disorders. Eur Respir J 1990; 3: 249-256 